Review

\title{
Graphene Oxide Derivatives and Their Nanohybrid Structures for Laser Desorption/Ionization Time-of-Flight Mass Spectrometry Analysis of Small Molecules
}

\author{
Seung-Woo Kim ${ }^{1}$, Sunbum Kwon ${ }^{2, *}$ and Young-Kwan Kim ${ }^{1, *(1)}$ \\ 1 Department of Chemistry, Dongguk University-Seoul, 30 Pildong-ro, Jung-gu, Seoul 04620, Korea; \\ swkim94@naver.com \\ 2 Department of Chemistry, Chung-Ang University, 84 Heukseok-ro, Dongjak-gu, Seoul 06974, Korea \\ * Correspondence: skwon@cau.ac.kr (S.-W.K.); kimyk@dongguk.edu (Y.-K.K.); \\ Tel.: +82-2-820-5201 (S.-W.K.); +82-2-2260-3214 (Y.-K.K.)
}

Citation: Kim, S.-W.; Kwon, S.; Kim, Y.-K. Graphene Oxide Derivatives and Their Nanohybrid Structures for Laser Desorption/Ionization Time-of-Flight Mass Spectrometry Analysis of Small Molecules. Nanomaterials 2021, 11, 288. https:// doi.org/10.3390/nano11020288

Academic Editor: Jarosław Mysliwiec Received: 24 December 2020

Accepted: 20 January 2021

Published: 22 January 2021

Publisher's Note: MDPI stays neutral with regard to jurisdictional claims in published maps and institutional affiliations.

\begin{abstract}
Matrix-assisted laser desorption/ionization (MALDI) has been considered as one of the most powerful analytical tools for mass spectrometry (MS) analysis of large molecular weight compounds such as proteins, nucleic acids, and synthetic polymers thanks to its high sensitivity, high resolution, and compatibility with high-throughput analysis. Despite these advantages, MALDI cannot be applied to MS analysis of small molecular weight compounds ( $<500 \mathrm{Da})$ because of the matrix interference in low mass region. Therefore, numerous efforts have been devoted to solving this issue by using metal, semiconductor, and carbon nanomaterials for MALDI time-of-flight MS (MALDI-TOF-MS) analysis instead of organic matrices. Among those nanomaterials, graphene oxide (GO) is of particular interest considering its unique and highly tunable chemical structures composed of the segregated $\mathrm{sp}^{2}$ carbon domains surrounded by $\mathrm{sp}^{3}$ carbon matrix. Chemical modification of GO can precisely tune its physicochemical properties, and it can be readily incorporated with other functional nanomaterials. In this review, the advances of GO derivatives and their nanohybrid structures as alternatives to organic matrices are summarized to demonstrate their potential and practical aspect for MALDI-TOF-MS analysis of small molecules.
\end{abstract}

Keywords: graphene oxide; nanocomposite; surface functionalization; laser desorption/ionization; mass spectrometry

\section{Introduction}

Matrix-assisted laser desorption/ionization (MALDI) technique, often combined with time-of-flight mass spectrometry (MALDI-TOF-MS), has been considered as a powerful and essential technique to analyze the intact molecular weight of high-molecular-weight compounds such as proteins [1], nucleic acids [2] and synthetic polymers [3] without their undesired fragmentation. This soft-ionization strategy has significantly contributed to the advances in chemical and biological researches based on its simple analysis process, miniscule sample consumption, high resolution, salt-tolerance, sensitivity and compatibility with high-throughput analysis [4,5]. The detailed mechanism of the MALDI process is still not fully understood, but it has been generally described by serial 3-step processes including laser energy transfer from matrix to analyte in their solid-state mixture upon laser irradiation, ionization by photochemical reaction and isolation of ionized analyte in excess matrix for mass spectrometric analysis [4]. Although MALDI-TOF-MS has been successfully applied to biological and polymer research fields for the molecular weight analysis of high-molecular-weight compounds, it cannot be directly harnessed to analyze low-molecular-weight compounds owing to the severe background interference in the low-mass region from detector saturation and/or photochemical side reactions by organic matrices such as 2,5-dihydroxybenzoic acid (DHB), $\alpha$-cyano-4-hydroxycinnamic 
acid (CHCA), sinapic acid, and caffeic acid [6]. For addressing this issue, many efforts have been devoted to the development of an efficient alternative to organic matrices that can be used in matrix-free laser desorption/ionization time-of-flight mass spectrometry (LDI-TOF-MS) [7-9]. Metal [10], semiconductor [11-14], and carbon nanomaterials [15-18] have been extensively investigated as potential mediators for the LDI-TOF-MS analysis of important low-molecular-weight compounds, including amino acids, saccharides, lipids, organic pollutants, and small peptides. The laser desorption/ionization (LDI) efficiency of those nanomaterials significantly depends on their chemical composition, size and morphology [12,19]. Therefore, development of an efficient nanomaterials-based LDITOF-MS platform for the analysis of those small molecules has been of central interest and has attracted much research attention from the material scientists [8]. Based on those efforts, important requirements, such as high surface area, colloidal stability, laser absorption capacity, electrical and thermal conductivity and photo-thermal conversion property, have been revealed to fabricate an efficient platform for LDI-TOF-MS analysis [20,21]. In addition to those colloidal nanomaterials, various nanoporous substrates including porous silicon [22] and titania [23] have also been investigated as a chip-based analytical platform for LDITOF-MS analysis of small molecules. Especially, porous silicon substrates are recognized as one of the representative chip-based LDI-TOF-MS platforms because of their excellent LDI efficiency derived from the high surface area, amenable surface and uniform mass signal distribution [24,25]. The efficiency of those nanoporous substrates in LDI-TOF-MS analysis has also been enhanced by surface modification $[26,27]$ and subsequent nanohybridization with other functional nanomaterials [28,29].

Among those various materials, carbon nanomaterials such as graphene [30-33], mesoporous carbon [34], graphene oxide (GO) [35], carbon nanotube (CNT) [36], and carbon $\operatorname{dot}(\mathrm{CD})[16,37]$ have been considered as excellent candidates because they meet most of the requirements as an efficient mediator for LDI-TOF-MS analysis of small molecules. In addition to the general requirements, the carbon materials can provide cost-effectiveness, functionalizable surface and strong affinity to various biomolecules [38] and environmental pollutants [39-41]. Especially, GO is a distinct carbon nanomaterial owing to its unique chemical structures composed of small segregated $\mathrm{sp}^{2}$ carbon domain surrounded by $\mathrm{sp}^{3}$ carbon matrix presenting oxygen containing functional groups [42]. Those $\mathrm{sp}^{2}$ carbon structures of GO derivatives play an important role in LDI-TOF-MS analysis by absorbing laser energy and converting it into thermal energy through the electron-phonon interaction for LDI of small molecules [35]. In this regard, Raman spectroscopy is a powerful and essential analytical tool to characterize the ordered and defected $\mathrm{sp}^{2}$ carbon structures of GO derivatives and their nanohybrid structures, which are closely related to their electron-phonon transition and then their efficiency in LDI-TOF-MS analysis [42-44]. GO derivatives are a complex family presenting the structural diversity depending on their synthetic and post-treatment processes. The physicochemical properties of GO derivatives greatly affect their behavior in LDI-TOF-MS analysis, and their detailed chemistry has been extensively reviewed elsewhere [45-52]. In addition, GO can be converted into graphene analogues by chemical and thermal reduction treatments for partial removal of oxygen containing functional groups, mainly hydroxyl and epoxy groups. However, there still remains residual oxygen containing functional groups on the reduced GO (RGO) because of the restricted degree of deoxygenation [52]. Thanks to these residual oxygen containing functional groups, GO and RGO derivatives can be hybridized with metal, metal oxide, and semiconductor nanomaterials by covalent and non-covalent surface modifications. The resulting nanohybrid structures can enrich thioloated, phosphorylated and/or aromatic biomolecules such as nucleic acids, amino acids, peptides and proteins through metalthiol, metal oxide-phosphate and $\pi-\pi$ interactions, respectively [53-56]. Based on those properties, GO and RGO derivatives and their nanohybrid structures have been actively investigated for LDI-TOF-MS analysis and exhibited a strong and versatile potential to analyze various kinds of important small molecules. There are several review articles which deal with the various nanomaterials-based matrices for LDI-TOF-MS analysis of 
small molecules [19]. Given the promising prospect and strong potential of GO-based nanohybrid structures for LDI-TOF-MS analysis, we think that GO derivatives and their nanohybrid structures should be solely reviewed with more detailed and comprehensive information.

\section{GO Derivatives for LDI-TOF-MS Analysis}

Dong et al. [57] reported that graphene can be harnessed as a novel matrix for LDI-TOFMS analysis of various small molecules, such as amino acids, polyamines, anticancer drugs, nucleosides and steroids, regardless of their polarity. It is noteworthy that the graphene used in this report was actually chemically-RGO flakes. Although the term graphene is only applicable to a single-layer of networked atomic $\mathrm{sp}^{2}$ carbon sheet compacted into a honeycomb lattice, it has been widely misused for RGO and few-layered graphite [58,59]. Therefore, we will use the term "RGO" rather than "graphene" throughout this review because most of the cited literature have utilized RGO for LDI-TOF-MS analysis of small molecules. In the report of Dong et Al., RGO was synthesized by using sodium dodecylbenzene sulfonate (SDBS) as a surfactant to prevent irreversible aggregation of RGO in aqueous media through the van der Waals and $\pi-\pi$ interactions between their basal planes [60]. Despite of the surfaceadsorbed SDBS on RGO, the resulting RGO exhibited many advantages for LDI-TOF-MS analysis of small molecules such as the high reproducibility, salt tolerance and applicability to the solid-phase extraction of squalene [57]. This report presents the possibility of GO derivatives as an efficient platform for LDI-TOF-MS analysis. However, it is of note that the surfactants on GO derivatives can interfere with the efficient energy transfer to analytes and solid-phase extraction, and thus the follow-up studies are generally excluded to use surfactants to prepare GO derivatives and their nanohybrid structures.

To address this issue, Zhou et al. [61] developed a RGO films-based LDI-TOF-MS platform by sequential fabrication processes including spin-coating of GO and subsequent chemical reduction by using hydrazine vapor. In this case, the RGO sheets were stably immobilized on a solid substrate and thus there was no demand of surfactants for dispersion in solvents. The resulting RGO films showed a higher efficiency and better reproducibility for LDI-TOF-MS analysis of an environmental pollutant, octachlorodibenzo-p-dioxin (OCDD), than the dispersed RGO powder. The limit of detection (LOD) of OCDD was found to be $500 \mathrm{pg}$ with RGO films and the obtained signal was higher than the RGO powder. This difference was attributed to the clean surface of RGO films, and their planar and well-interconnected structures which facilitate the $\pi-\pi$ interaction with OCDD, laser energy absorption, and energy transfer to OCDD for LDI-TOF-MS analysis. This report clearly shows that the advantages of chip-based LDI-TOF-MS platform.

Lu et al. [62] demonstrated that the efficiency of RGO flakes in LDI-TOF-MS analysis was higher under negative ionization mode than positive ionization mode. Based on their results, the mass spectra of peptides, amino acids, fatty acids, nucleosides and nucleotides can be obtained by using RGO flakes under both positive and negative ionization modes, but there was a clear difference in mass spectra obtained under positive and negative ionization modes. The mass spectra obtained under positive ionization mode were composed of many kinds of multiple cationic adducts with proton and alkali metals such as $[\mathrm{M}+$ $\mathrm{H}]^{+},[\mathrm{M}+\mathrm{Na}]^{+},[\mathrm{M}+\mathrm{K}]^{+},[\mathrm{M}+2 \mathrm{Na}-\mathrm{H}]^{+}$and $[\mathrm{M}+\mathrm{Na}+\mathrm{K}-\mathrm{H}]^{+}$. By stark contrast, the mass spectra obtained under a negative ionization mode were only composed of a single deprotonated form such as $[\mathrm{M}-\mathrm{H}]^{-}$. Since the formation of multiple adducts makes identification of analytes complicated, the applicability of RGO flakes to a negative ionization mode facilitates its wide-spread usage for LDI-TOF-MS analysis [30,37,62].

The size and structure of graphene derivatives might also have significant influence on the LDI-TOF-MS analysis. Liu et al. [63] investigated the LDI efficiency of graphene derivatives such as graphene, GO and RGO for LDI-TOF-MS analysis of small molecules under negative ionization mode. According to the results, the graphene prepared by chemical vapor deposition showed no activity as a matrix for LDI-TOF-MS analysis, but GO and RGO flakes presented a high efficiency for LDI-TOF-MS analysis of flavonoids 
and coumarin derivatives. Interestingly, the LDI efficiency of GO flakes was much higher than that of RGO flakes even at 1 pmol of flavonoids, which is presumably attributed to the abundant carboxylic acid groups on GO flakes. The authors also explored size effect of GO flakes on LDI-TOF-MS analysis and found that millimeter-sized GO flakes provide a higher LDI efficiency than micrometer-sized GO flakes for the analysis of flavonoids [63].

Kim et al. [64] investigated the size influence of GO flakes on their fragmentation behavior during LDI-TOF-MS analysis of small molecules (Figure 1a). Considering that the fragmentation of GO flakes mainly occurs on the defect sites and labile structures composed of epoxide groups, the fragmentation of GO flakes can be strongly dependent on their lateral dimension [64]. The GO flake larger than $5 \mu \mathrm{m}$ in their lateral dimension underwent severe fragmentation compared to the GO flakes smaller than $1 \mu \mathrm{m}$ (Figure 1b). This observation was attributed to the increased density of defects and epoxide groups on the basal plane GO flakes with their lateral dimension [65]. The results implied that the smaller GO flakes lead to the less fragmentation during LDI-TOF-MS analysis, and this hypothesis was further confirmed with LDI-TOF-MS analysis by using nano-sized GO (NGO) flakes which obtained clear mass spectra of small molecules without interference from the fragmentation of GO flakes in low mass region [64]. By using NGO as a matrix, organic pollutants such as benzoyldibenzo-pdioxin (BDPD), benzo[a]pyrene (B[a]P), and perfluorobutyric acid (PBA) were analyzed with LDI-TOF-MS and the LOD was determined as $15 \mathrm{fg}, 150 \mathrm{fg}$, and $15 \mathrm{pg}$, respectively. Overall, these outcomes clearly show the potential of LDI-TOF-MS analysis to be directly utilized for investigating the chemical structure of $\mathrm{GO}$ derivatives.

a)

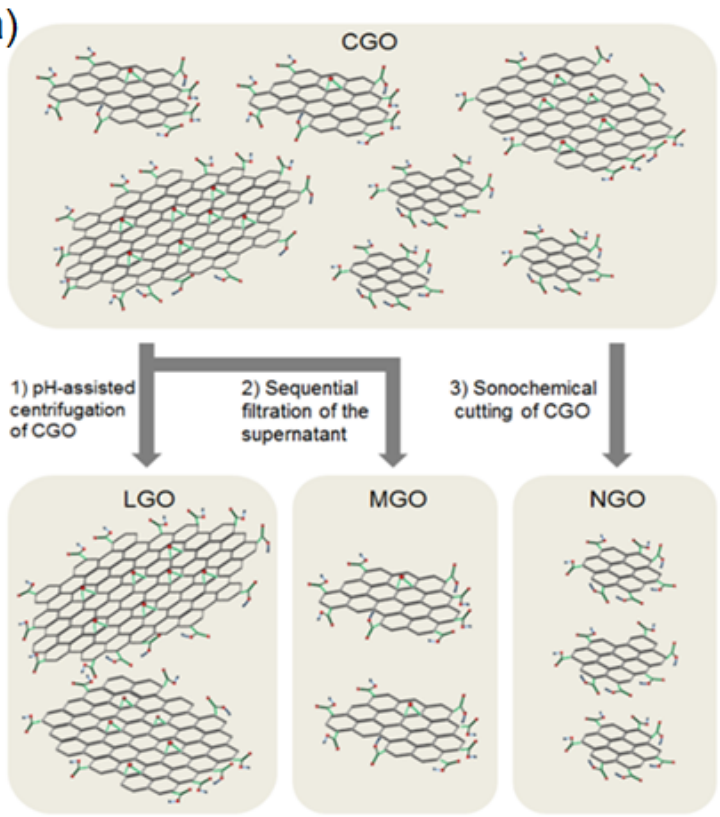

b)

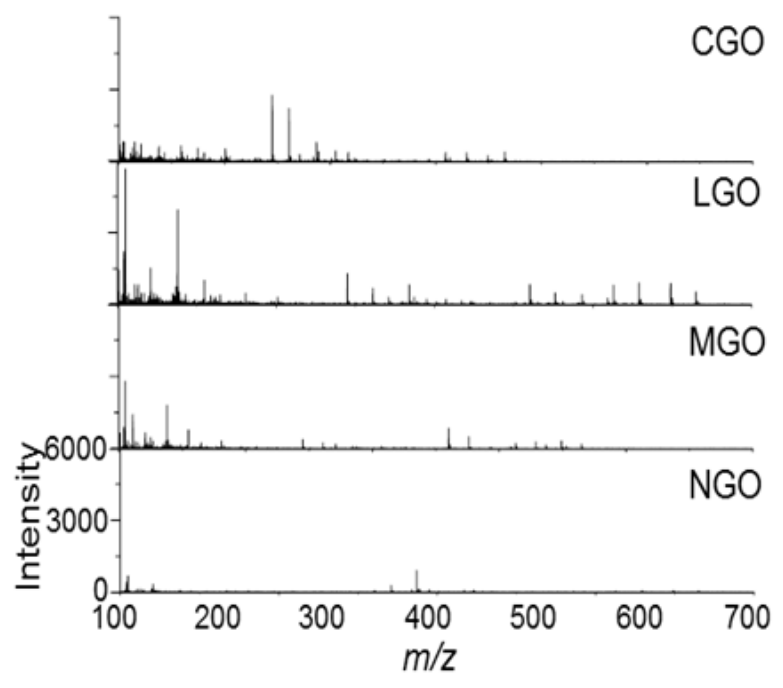

Figure 1. (a) A schematic diagram of size-fractionalization of GO flakes depending on their lateral of dimension. (b) LDITOF-MS spectra of small molecules obtained by using size-fractionalized GO flakes. Adapted with permission from ref. [64]. Copyright 2015 Wiley-VCH.

The origin of the fragmentation behavior of GO derivatives in LDI-TOF-MS analysis was further investigated [66,67], as the true structure of GO sheets is debated owing to the recent discovery of highly oxidized species present on their surface [68]. The origin of the fragmentation could be traced to the direct fragmentation of a core graphene-like sheet or the detachment of the surface-adsorbed oxidative debris (OD). To determine the source of fragmentation, a graphene-like sheet and OD were separated from as-synthesized $\mathrm{GO}(\mathrm{aGO})$ through a base-washing process (Figure 2a), and the resulting graphene-like sheet (bwGO) and OD were subjected to LDI-TOF-MS analysis under identical conditions (Figure 2b). Comparison of LDI-TOF-MS spectra of bwGO to that of aGO showed 
that aGO exhibited mass peaks attributed to both pure and oxidized carbon clusters, while bwGO presented much stronger mass peaks solely due to the pure carbon clusters (Figure 2c). These results indicate that the fragmentation of GO sheets originates from both the core graphene-like sheet and the detachment of the surface-adsorbed OD; however, the separation process leads to the partial reduction of these GO sheet constituents.

a)
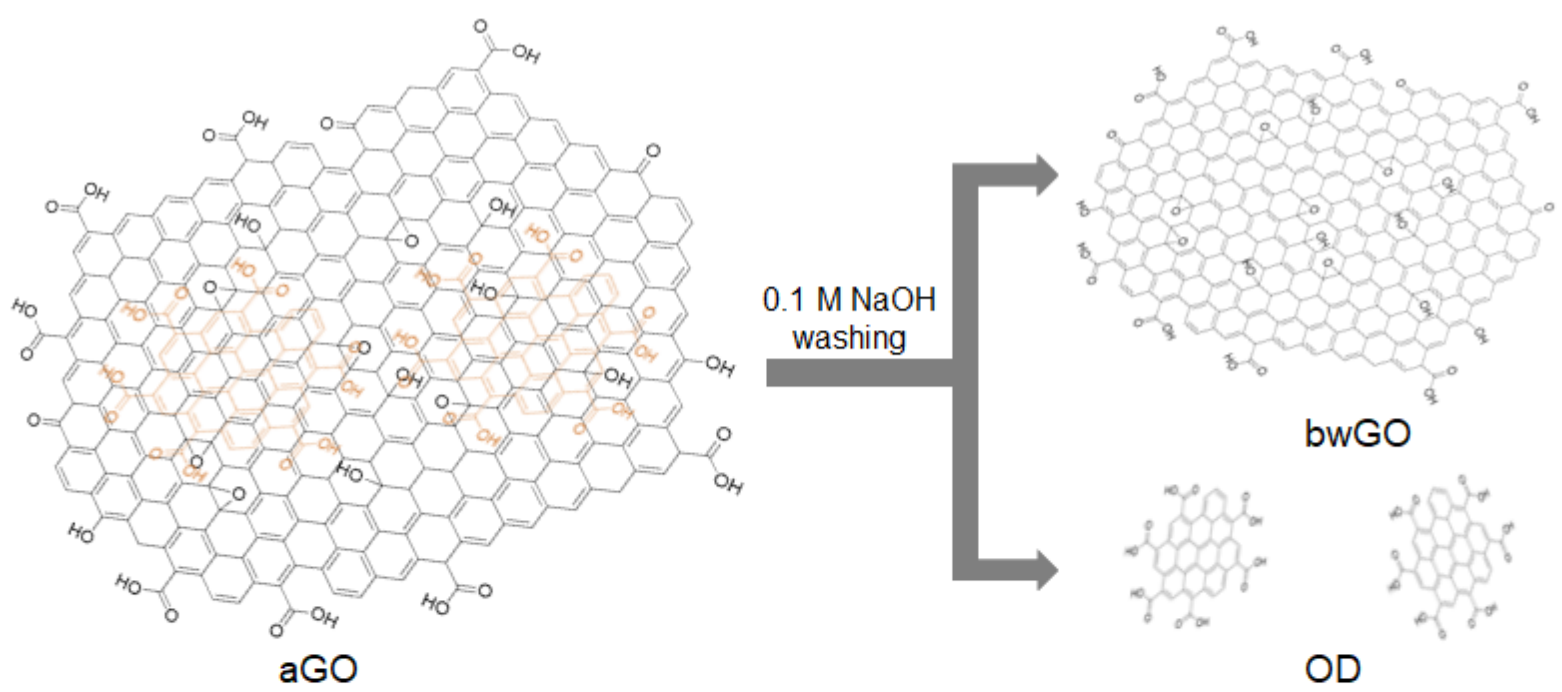

b)
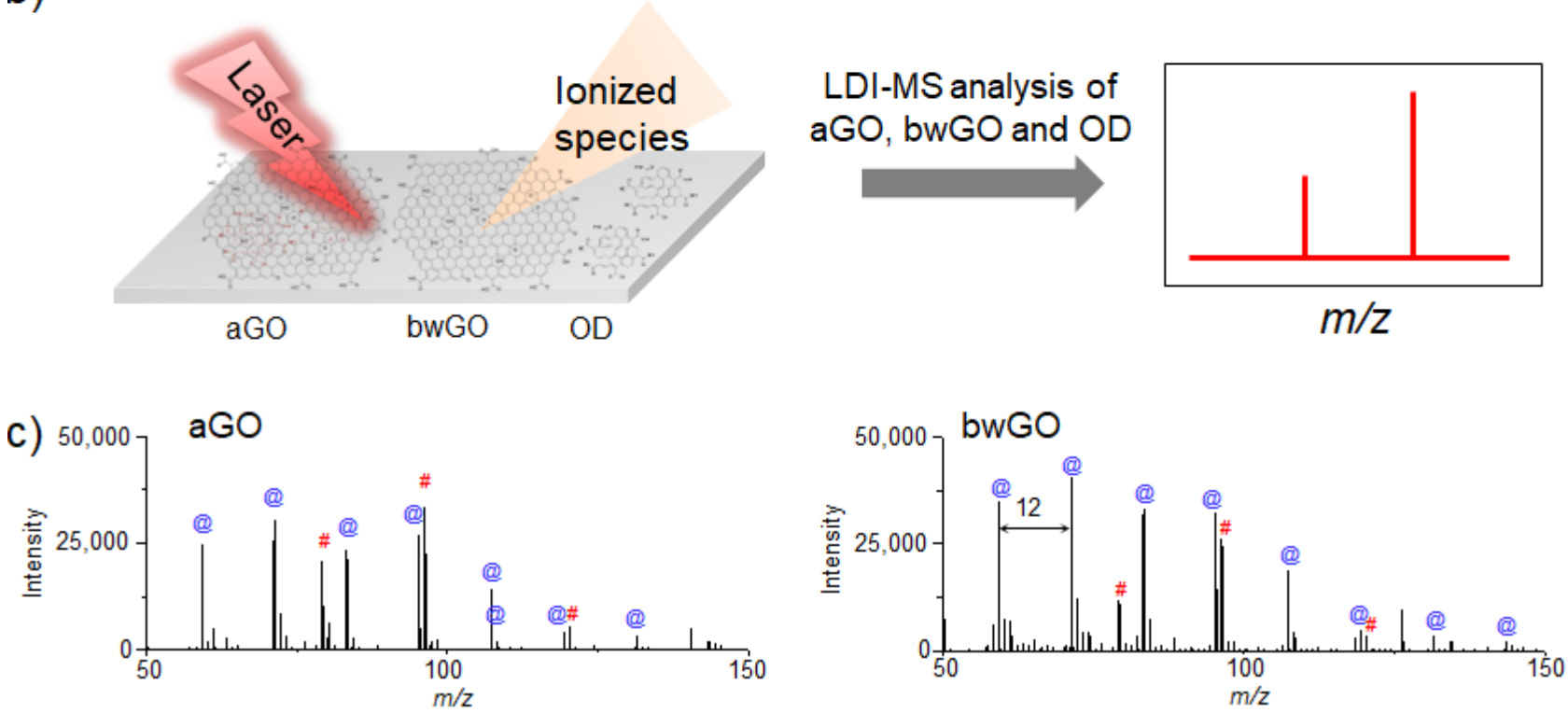

Figure 2. Schematic diagrams of (a) the separation process of OD and bwGO from aGO by washing with $0.1 \mathrm{M} \mathrm{NaOH}$, and (b) LDI-TOF-MS analysis process of the obtained aGO and bwGO. (c) LDI-TOF-MS spectra of aGO and bwGO. The symbol @ in blue color corresponds to the carbon cluster ions and the symbol \# in red color corresponds to the oxidized carbon cluster ions. Adapted from ref. [66] with permission from The Royal Society of Chemistry.

In addition, the influence of OD on the efficiency of LDI-TOF-MS analysis was further investigated by comparing aGO and bwGO. The efficiency of the LDI-TOF-MS analysis of various analytes, was higher with bwGO than with aGO regardless of their chemical structure and molecular weight (Figure 3). The LOD of small molecules with bwGO was determined to be approximately $10 \mathrm{pmol}$ which is lower than that with aGO (100 pmol). This demonstrates that the photo-thermal conversion efficiency of GO derivatives can be enhanced simply by removing the surface-adsorbed OD [67]. 


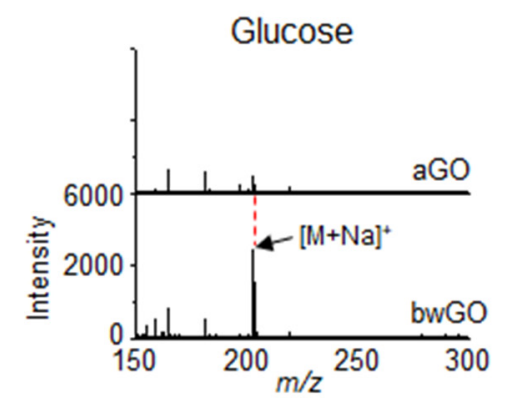

Arginine

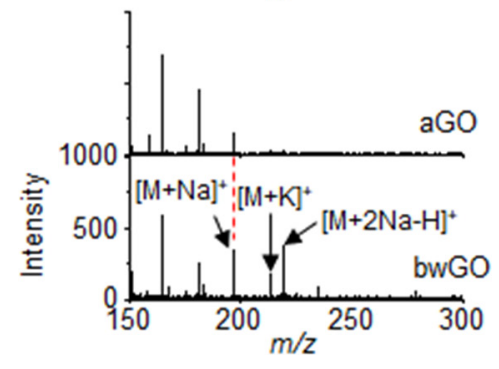

Sorbitol

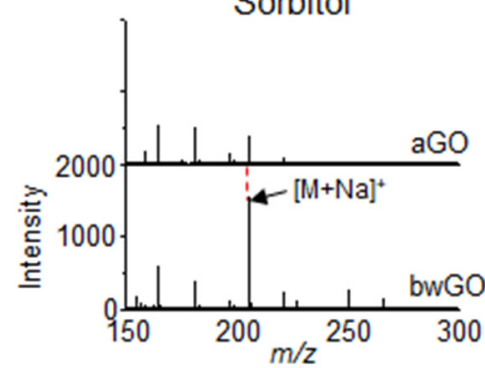

Histidine

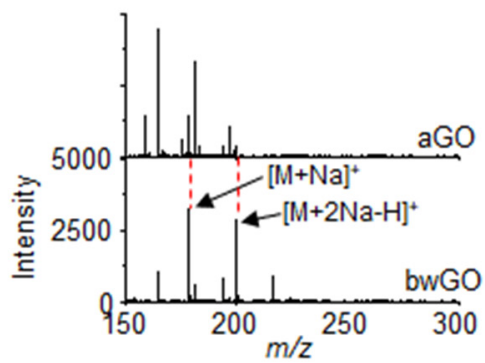

Sucrose

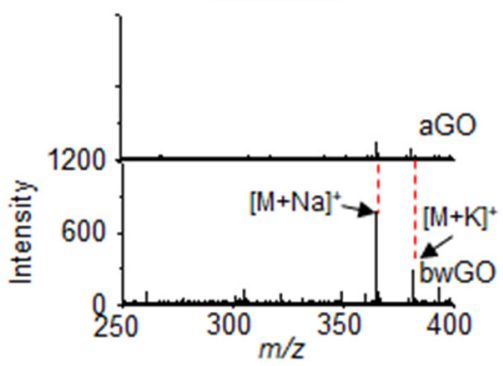

Phenylalanine

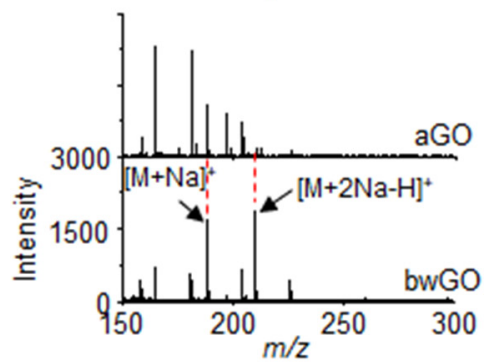

Figure 3. LDI-TOF-MS spectra of small molecules such as glucose, sorbitol, sucrose, arginine, histidine, and phenylalanine obtained with aGO and bwGO. Reproduced with permission from ref. [67]. Copyright (2019) Japan Society for Analytical Chemistry.

\section{GO/CNT Hybrid Structures for LDI-TOF-MS Analysis}

As discussed in the former section, GO derivatives have been extensively investigated for LDI-TOF-MS analysis of small molecules, but their direct application is relatively restricted in comparison with other carbon nanomaterials such as CNT and CD [36,37]. This is owed to their relatively low efficiency of photothermal conversion and low photochemical stability under the irradiation by high-power lasers during LDI-TOF-MS analysis [64]. The former feature results in low efficiency in LDI-TOF-MS analysis, and the latter feature leads to severe fragmentation that generates background interference in the low-mass region $[64,67]$. These problems are major obstacles to be overcome for the successful application of GO derivatives to LDI-TOF-MS analysis. Lee et al. [69] demonstrated that the hybrid films of GO and amine-functionalized multi-walled carbon nanotube (MWCNT$\mathrm{NH}_{2}$ ) can be utilized as an efficient platform for the lipase-activity assay based on the LDI-TOF-MS analysis. The hybrid films were fabricated by the sequential assembly of GO and MWCNT-NH $\mathrm{N}_{2}$ on amine-functionalized solid substrates through the strong electrostatic interaction between negatively-charged oxygen containing functional groups of GO and positively-charged amine groups of $\mathrm{MWCNT}-\mathrm{NH}_{2}$. After the sequential electrostatic assembly, the resulting GO/MWCNT-NH 2 hybrid films were thermally treated to induce formation of covalent linkages which resulted in increase in their stability during LDITOF-MS analysis [70]. Therefore, the hybrid films presented negligible interference in the low mass region because of their covalently connected structures. The GO/MWCNT$\mathrm{NH}_{2}$ hybrid films also exhibited a high efficiency for LDI-TOF-MS analysis of lipids and fatty acids, implying that there is a synergistic effect from the interfaces between GO and MWCNT- $\mathrm{NH}_{2}$ that provides high laser energy absorption and photothermal conversion for LDI-TOF-MS analysis [69].

Kim et al. [71] investigated how to develop an optimized hybrid film composed of GO and MWCNT derivatives. Various combinations of GO and MWCNT derivatives were systematically exploited to prepare their hybrid films such as GO/MWCNT-NH${ }_{2}$, $\mathrm{RGO} / \mathrm{MWCNT}$, and RGO/MWCNT-NH 2 (Figure 4a). As control, the individual GO, RGO and MWCNT-NH $\mathrm{N}_{2}$ films were also prepared to clearly reveal the possible synergistic effect from their hybridized structures. The detailed fabrication processes and structures of those 
hybrid films are presented in Figure 4a,b. Among the fabricated films, GO/MWCNT-NH hybrid films exhibited the highest performance for LDI-TOF-MS analysis of small molecules in terms of salt tolerance, homogeneous mass signal, sensitivity, accuracy and resolution (Figure 4c). The LOD was determined to be approximately 1 to 100 pmol. In addition, there was less fragmentation of GO/MWCNT- $\mathrm{NH}_{2}$ hybrid films than the other hybrid films during LDI-TOF-MS analysis, and this stability was attributed to the covalently-linked structures between the substrate, GO flakes, and $\mathrm{MWCNT}-\mathrm{NH}_{2}$ [71]. This report suggests that the GO and MWCNT-NH${ }_{2}$ hybrid film is a promising candidate as an efficient platform for LDI-TOF-MS analysis of small molecules.

a)

b)
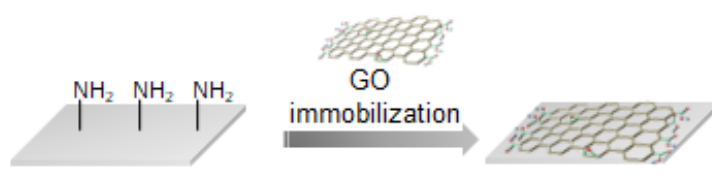

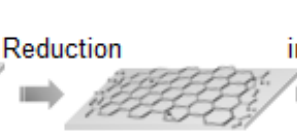

2) RGO

MWCNT

immobilization

1) $\mathrm{GO}$

$\mathrm{NH}_{2} \mathrm{NH}_{2}$ $\underset{\text { immobilization }}{\text { MWCNT-NH }} \overbrace{\mathrm{NH}_{2}}^{\mathrm{NH}_{2}}$
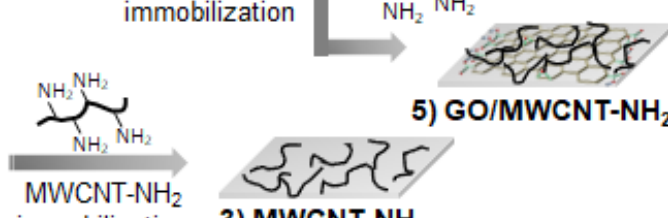

immobilization
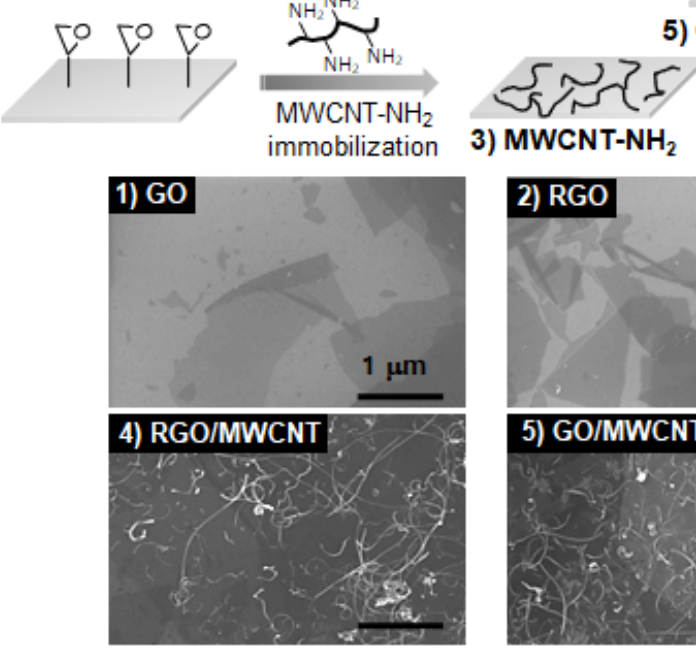

5) GO/MWCNT-NH

3) MWCNT-NH
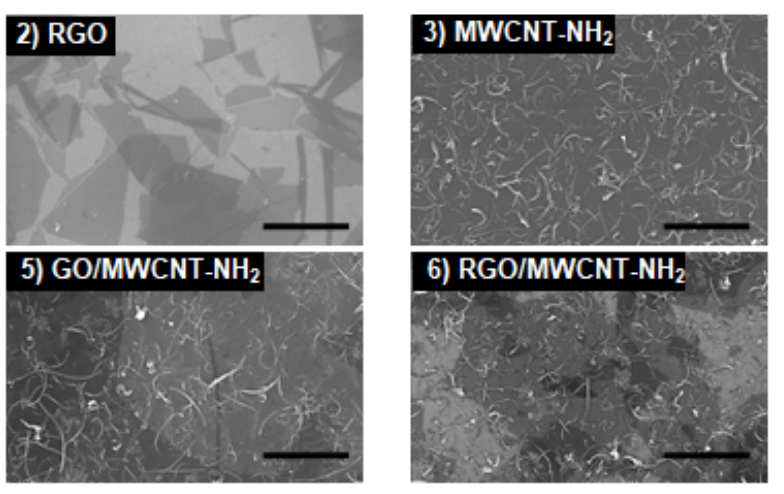

c)
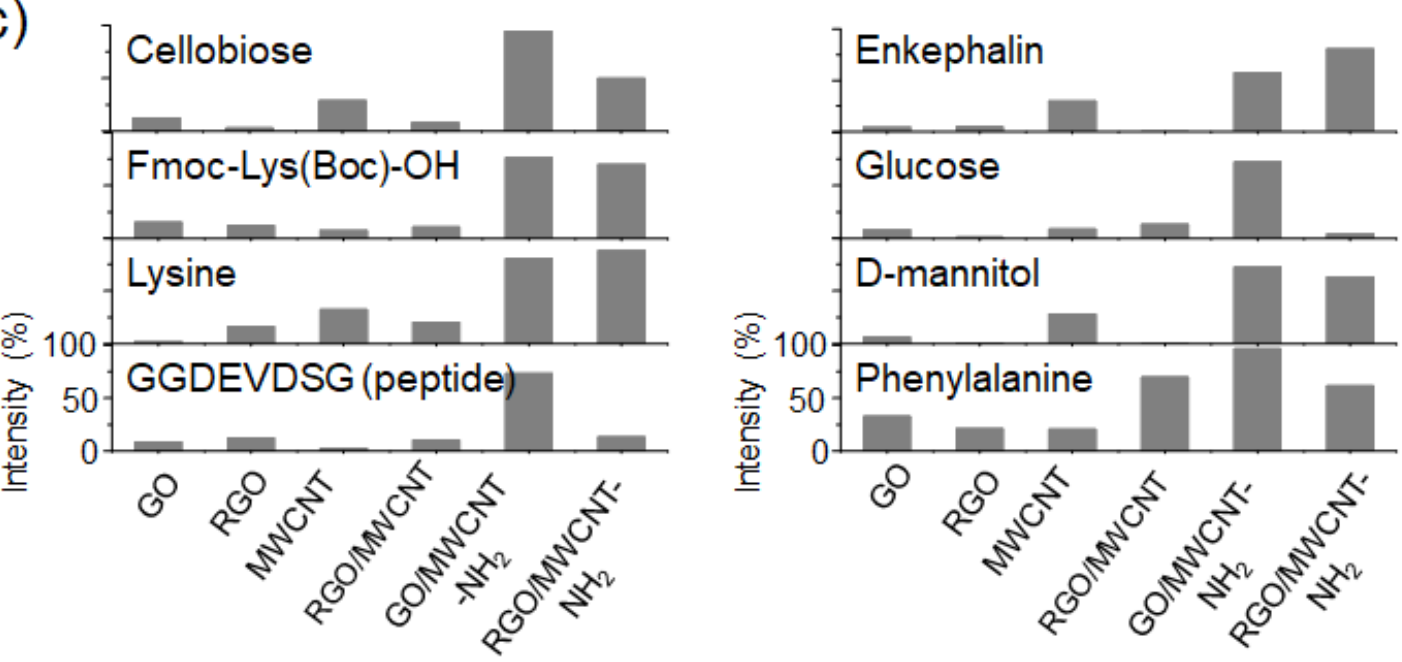

Figure 4. (a) Fabrication processes and (b) scanning electron microscopy (SEM) images of GO, RGO, MWCNT-NH , $^{2}$ $\mathrm{RGO} / \mathrm{MWCNT}, \mathrm{GO} / \mathrm{MWCNT}-\mathrm{NH}_{2}$ and $\mathrm{RGO} / \mathrm{MWCNT}_{-} \mathrm{NH}_{2}$ nanohybrid films. (c) The relative mass signal intensities of various small molecules such as cellobiose, Leu-enkephalin, Fmoc-Lys(Boc)-OH, phenylalanine, glucose, lysine, D-mannitol and GGDEVDSG peptide. Adapted with permission from ref. [71]. Copyright 2011 American Chemical Society. 
Then, they explored the structural effect of GO/MWCNT- $\mathrm{NH}_{2}$ hybrid films such as thickness and surface roughness [72]. It is well known that the oppositely charged GO flakes and MWCNT- $\mathrm{NH}_{2}$ can be alternatively assembled on a solid substrate by layer-by-layer (LBL) assembly technique [73-75]. Based on this principle, GO flakes and MWCNT-NH were successively assembled on a substrate with an alternating structure (Figure 5a), and thus the laser energy absorption capacity, thickness and surface roughness of the resulting $\mathrm{GO} / \mathrm{MWCNT}-\mathrm{NH}_{2}$ hybrid films were precisely controlled by the number of LBL assembly cycles (Figure 5a-c) [72]. The thickness and surface roughness of GO/MWCNT-NH ${ }_{2}$ hybrid films are directly related to their laser energy absorption capacity and interfacial area with small molecules, respectively [71,72]. By using the LBL assembled GO/MWCNT-NH hybrid films, they found that the LDI-TOF-MS analysis efficiency of GO/MWCNT-NH hybrid films increased with the number of LBL assembly up to 5 cycles, but it started to decrease with further LBL assembly. This interesting nonlinear behavior was attributed to the fragmentation of LBL assembled GO/MWCNT-NH$H_{2}$ hybrid films by too much local heating induced by laser irradiation. The results indicated that the LDI-TOF-MS analysis efficiency of GO/MWCNT- $\mathrm{NH}_{2}$ hybrid films is greatly affected by their physical structures such as thickness and surface roughness. The LOD of small molecules on five layered $\mathrm{GO} / \mathrm{MWCNT}-\mathrm{NH}_{2}$ hybrid films were determined to be 10 pmol for cellobiose, Leu-enkephalin and phenyl alanine, and 100 pmol for glucose, lysine and leucine.
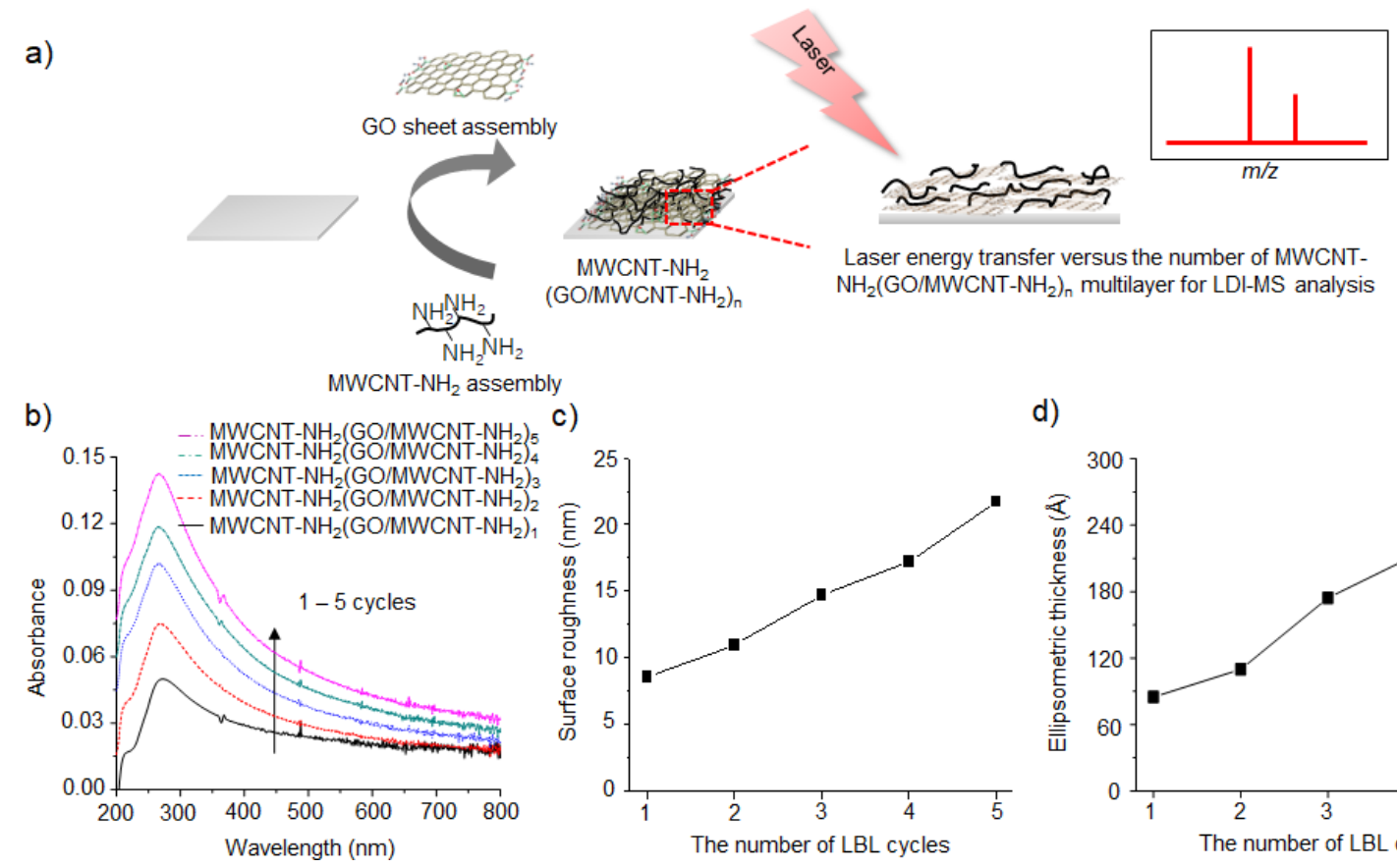

c)
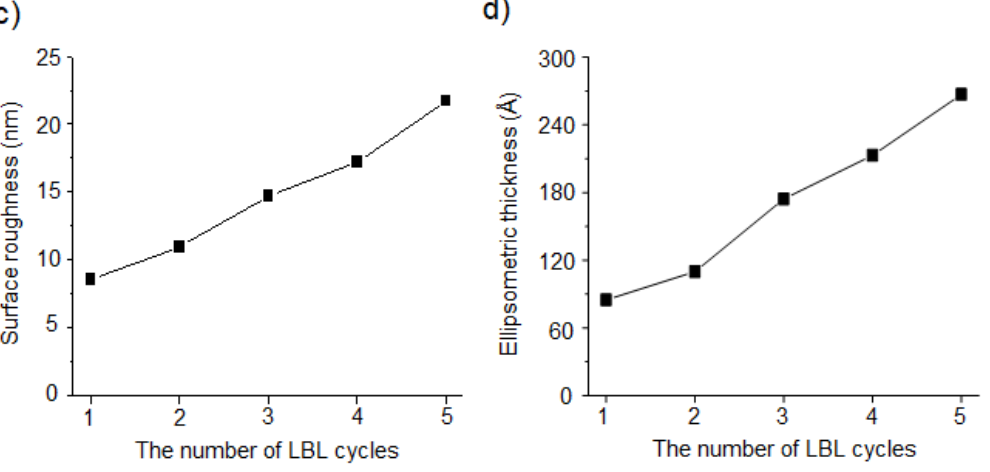

Figure 5. (a) Fabrication process, (b) UV-Vis absorption spectra, (c) surface roughness and (d) ellipsometric thickness of GO and MWCNT-NH 2 nanohybrid films prepared with the different number of LBL assembly cycles. Adapted with permission from ref. [72]. Copyright 2012 American Chemical Society.

\section{GO/Metal Hybrid Structures for LDI-TOF-MS Analysis}

Metallic nanoparticles (NPs) have been extensively explored for LDI-TOF-MS analysis of small molecules based on their well-defined synthesis, surface chemistry, high optical absorption and photo-thermal conversion [76-81]. Therefore, the hybridization of GO derivatives with metallic NPs has been considered a promising approach to the improve efficiency of LDI-TOF-MS analysis of small molecules. Kim et al. [82] demonstrated a simple approach to prepare the Au NPs/GO hybrid films. GO films were fabricated by immobilization of GO flakes on amine-functionalized glass substrates and then treated with polyallylamine hydrochloride (PAAH) to introduce primary amine groups on the GO 
films (Figure 6a). Five nm-sized Au NPs were incorporated onto the PAAH-functionalized GO (PAAH-GO) films by electrostatic interaction and further grown by the seed-mediated growth process (Figure 6a) [83,84]. The resulting Au NPs/PAAH-GO hybrid films exhibited high efficiency in LDI-TOF-MS analysis of small molecules without interference in low mass region (Figure $6 \mathrm{~b}$ ) and the LOD of small molecules were estimated to be $100 \mathrm{pmol}$. For systematic investigation of interfacing-structure effect between Au NPs and GO films, $\mathrm{Au}$ NPs on PAAH-treated glass, pyrene ethyleneglycol amine-functionalized GO (PEA-GO) and PAAH-GO films were parallelly compared as an analytical platform for LDI-TOFMS analysis of small molecules. Interestingly, the analytical efficiency was highest on the Au NPs/PAAH-GO hybrid films among the tested films (Figure 6c), which implies that the hybridization of GO derivatives with metallic NPs considerably enhances their LDI-TOF-MS efficiency for analysis of small molecules.

a)

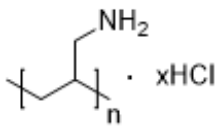

High density Au seed immobilization

PAAH adsorption

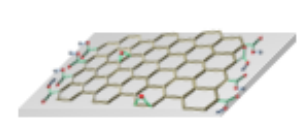

b)
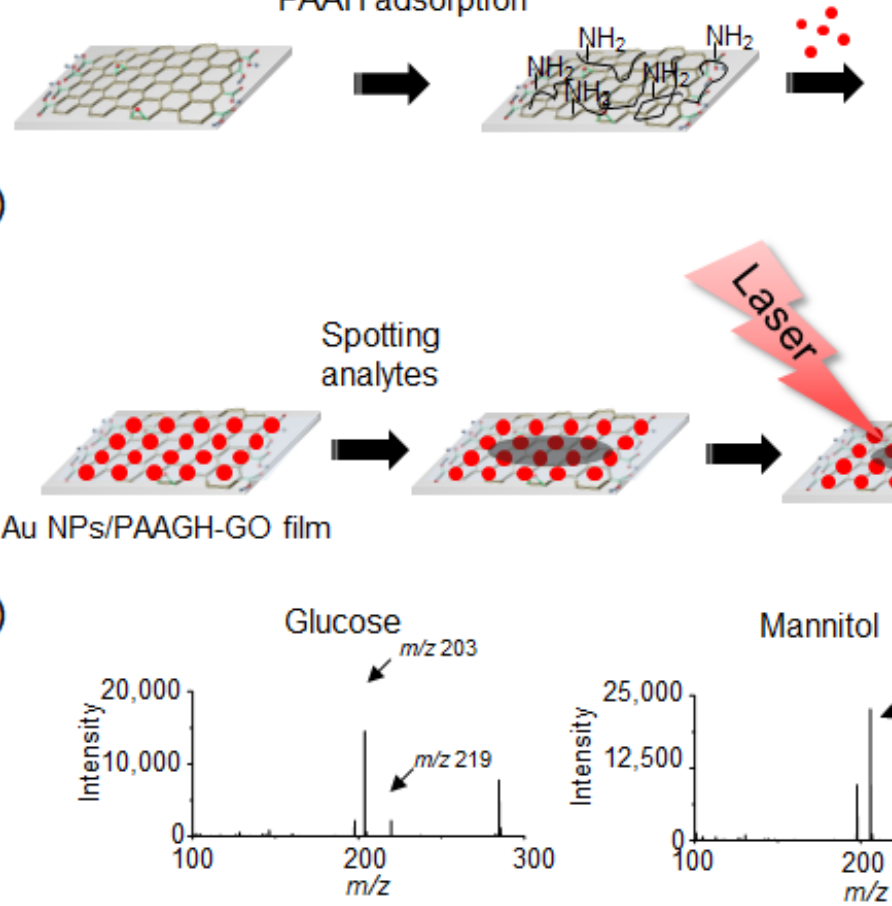

Phenylalanine

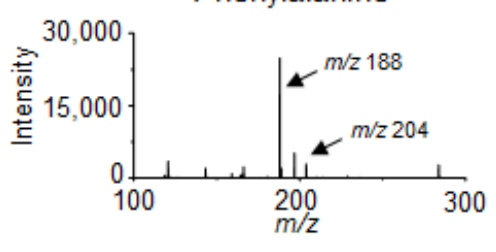

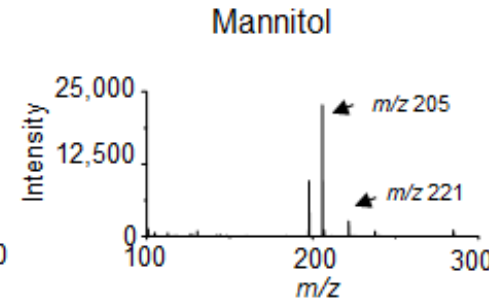

Glutamine

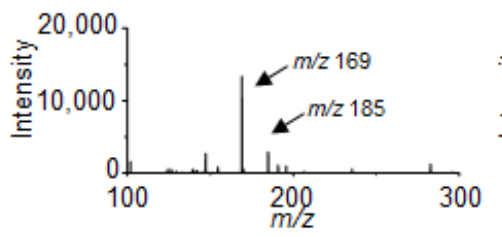

Ionized species

Au NPs/PAAH-GO film

\section{Seed-mediated growth}

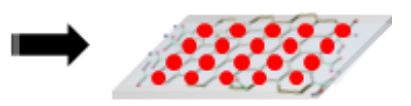


controlled thickness by the number of LBL cycles. To find the correlation between the thickness of hybrid films and LDI-TOF-MS analysis efficiency, 2, 5, 10, 15, and 20 layers of Au NPs/RGO hybrid films were serially fabricated and applied to LDI-TOF-MS analysis of small molecules. With an increase of the number of layers, the optical absorption at $\mathrm{N}_{2}$ laser wavelength $(337 \mathrm{~nm})$ almost linearly increased and thus the LDI-TOF-MS analysis efficiency was also enhanced up to 10 LBL assembly cycles. However, the LDI-TOF-MS efficiency was diminished with further LBL assembly because the deep infiltration of analytes into the thick hybrid films impeded their efficient desorption/ionization. The optimized 10 layered Au NPs/RGO films exhibited high efficiency in LDI-TOF-MS analysis of amino acids and glutathione without interference in the low mass region at $150 \mathrm{pmol}$ of various small molecules. This high performance was attributed to the combination of high thermal conductivity of RGO flakes and low heat capacity of Au NPs.

The hybridization of Ag NPs with GO derivatives for LDI-TOF-MS analysis of small molecules was also thoroughly explored by Hong et al. [86]. They harnessed LBL assembly process of poly(diallyldimethylamonium chloride) (PDDAC) and AgNPs/RGO flakes to fabricate Ag NPs/RGO hybrid films with a controlled porosity and thickness (Figure 7). Based on their results, it was confirmed that the formation of Ag cluster ions from Ag NPs, one of main problems of metallic NPs as a LDI-TOF-MS platform, can be prevented with enhanced LDI efficiency by hybridization of RGO flakes. Interestingly, carbon ion clusters were also not formed from Ag NPs/RGO flakes hybrid films during LDI-TOF-MS analysis. This interesting behavior was presumably attributed to their highly porous structures and strong electrostatic interaction between PDDAC, Ag NPs and RGO flakes [85]. Given no interference from metal and carbon ion clusters, Ag NPs/RGO hybrid films exhibited a high applicability to LDI-TOF-MS analysis platform for carboxyl-containing small molecules such as amino acids, fatty acids, peptides and dicarboxyl-contained organic molecules (Figure 7).
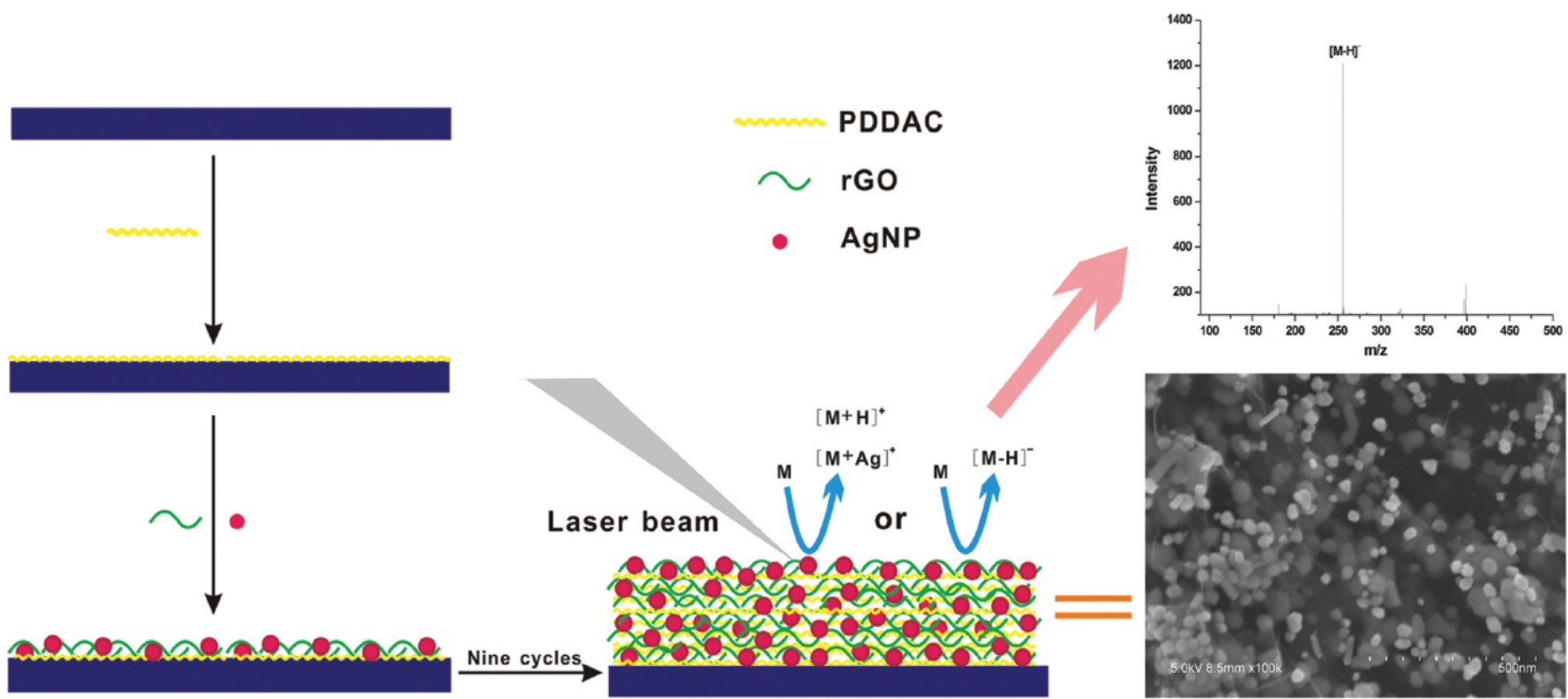

Figure 7. Preparation process and structure of Ag NPs/RGO nanohybrid films, and their application to LDI-TOF-MS analysis of small molecules. Reproduced from ref. [86] with permission from The Royal Society of Chemistry.

$\mathrm{Au}$ NPs/GO hybrid structures can also be harnessed for selective enrichment because the surface functionalization chemistry of Au NPs is well established for the enrichment of various specific targets [87]. Recently, Li et al. [88] reported the synthesis of a porous bead composed of GO and Au NPs presenting abundant binding sites for selective enrichment of N-linked glycopeptides. The porous GO beads were prepared by freeze-drying of a mixture droplet consisting of GO flakes, polyethyleneimine (PEI) and poly(ethylene glycol) 
diglycidyl ether (PEGDE), and thermally treated for their structural stabilization. Then, the GO beads were directly utilized as a support for direct synthesis of Au NPs on their surface and the resulting Au NPs/GO porous hybrid beads were further functionalized with glutathione to provide abundant binding sites for multivalent interaction with N-linked glycopeptides. The N-linked glycopeptides possess higher hydrophilicity than non-linked glycopeptides, and thus they can be strongly bound to the surface of Au NPs/GO porous hybrid beads. By using the porous hybrid beads, N-linked glycopeptides were successfully enriched and thus efficiently analyzed by using MALDI-TOF-MS with a high selectivity, reproducibility, and low LOD of $2 \mathrm{fmol}$.

\section{GO/Metal Oxide Hybrid Structures for LDI-TOF-MS Analysis}

The magnetic solid phase extraction (MSPE) of environmental pollutants is also a critical application of $\mathrm{Fe}_{3} \mathrm{O}_{4} \mathrm{NPs} / \mathrm{RGO}$ nanohybrid structures. In natural water, there are many kinds of antibiotics that are regarded as organic pollutants owing to their potential adverse effect on human health and ecosystems [89-91]. Tang et al. [92] reported that the MSPE of quinolones (QNs), which are one of the widely-used antibiotics causing a significant concern, by using $\mathrm{Fe}_{3} \mathrm{O}_{4}$ NPs/GO nanohybrid structures in various water sources. Since the QNs are generally present at low concentration in natural water, there is a strong demand on a facile way to enrich them for the efficient analysis [93,94]. The $\mathrm{Fe}_{3} \mathrm{O}_{4}$ NPs/GO nanohybrid structures were prepared by covalent incorporation of 3aminopropyltriethoxysilane (APTES)-functionalized $\mathrm{Fe}_{3} \mathrm{O}_{4} \mathrm{NPs}\left(\mathrm{Fe}_{3} \mathrm{O}_{4} \mathrm{NPs}-\mathrm{NH}_{2}\right)$ on the surface of GO flakes through $\mathrm{N}$-(3-dimethylaminopropyl)- $\mathrm{N}^{\prime}$-ethylcarbodiimide (EDC)/Nhydroxysuccinimide (NHS) coupling [93]. The resulting $\mathrm{Fe}_{3} \mathrm{O}_{4} \mathrm{NPs}-\mathrm{NH}_{2} / \mathrm{GO}$ nanohybrid structures were harnessed for MSPE of 12 kinds of QNs such as enoxacin, norfloxacin, ciprofloxacin, pefloxacin, fleroxacin, gatifloxacin, enrofloxacin, levofloxacin, sparfloxacin, danofloxacin, difloxacin, and lomefloxacin [92]. For the optimization of MSPE and MALDITOF-MS processes, various experimental factors including acidity, extraction time, amount of adsorbent, elution solution and desorption time were systematically explored and then the enriched QNs on $\mathrm{Fe}_{3} \mathrm{O}_{4} \mathrm{NPs}-\mathrm{NH}_{2} / \mathrm{GO}$ nanohybrid structures were analyzed by using a surfaced-immobilized CHCA on SBA-15 treated with 3-APTES (SBA-15-NH 2 /CHCA) as a matrix. All QNs were successfully detected from real water samples from the Hai river by combination of MSPE and MALDI-TOF-MS analysis without background interference. This result confirmed the practical applicability of $\mathrm{Fe}_{3} \mathrm{O}_{4} \mathrm{NPs}-\mathrm{NH}_{2} / \mathrm{GO}$ nanohybrid structures as an adsorbent for MSPE of a trace amount of environmental pollutants.

Although the previous reports only utilize $\mathrm{Fe}_{3} \mathrm{O}_{4} \mathrm{NPs} / \mathrm{GO}$ nanohybrid structures as a MSPE material [95], $\mathrm{Fe}_{3} \mathrm{O}_{4} \mathrm{NPs} / \mathrm{GO}$ nanohybrid structures can be directly applied to LDITOF-MS analysis after MSPE of specific target analytes because both GO and $\mathrm{Fe}_{3} \mathrm{O}_{4} \mathrm{NPs}$ are an efficient material for LDI-TOF-MS analysis of small molecules [61,96]. Chien et al. [97] demonstrated that the $\mathrm{Fe}_{3} \mathrm{O}_{4} \mathrm{NPs} / \mathrm{GO}$ nanohybrid structures can be simultaneously used for MSPE and then LDI-TOF-MS analysis of glimepride, which is one of the representative medicines to reduce blood glucose levels in the patients of diabetes but also abused to induce narcotic effect. The $\mathrm{Fe}_{3} \mathrm{O}_{4} \mathrm{NPs} / \mathrm{GO}$ nanohybrid structures were prepared by incorporation of pre-synthesized $\mathrm{Fe}_{3} \mathrm{O}_{4}$ NPs on the surface of GO flakes, having the different number of layers through an emulsion and solvent evaporation process. By using the $\mathrm{Fe}_{3} \mathrm{O}_{4}$ NPs/GO nanohybrid structures, the LOD of glimepiride was determined to be as $284 \mathrm{pmol}, 253 \mathrm{pmol}$, and $26 \mathrm{pmol}$ for $\mathrm{Fe}_{3} \mathrm{O}_{4}$ NPs/GO nanohybrid structures prepared with single layered, 2-4 layered, and 4-8 layered GO flakes, respectively [95]. Those results clearly imply that the $\mathrm{Fe}_{3} \mathrm{O}_{4} \mathrm{NPs} / \mathrm{GO}$ nanohybrid structures are one of the promising materials for MSPE and LDI-TOF-MS analysis and the number of GO layers has critical influence on the efficiency of LDI-TOF-MS analysis on the $\mathrm{Fe}_{3} \mathrm{O}_{4} \mathrm{NPs} / \mathrm{GO}$ nanohybrid structures.

Even without the MSPE process, metal oxide/GO nanohybrid structures can be considered an important material for LDI-TOF-MS analysis. In this regard, Kim et al. [98] demonstrated that the $\mathrm{ZnO} / \mathrm{RGO}$ nanohybrid structures can be directly applied to wafer- 
level detection of organic contaminations with LDI-TOF-MS analysis (Figure 8a). The detection of organic contaminants on $\mathrm{Si}$ wafer has been a critical issue to improve the yield of semiconductor fabrication processes and thus there is a demand on the analytical tool, which can provide the localized information of chemical structures of the residual organic contaminants on the semiconductor devices [99]. Therefore, LDI-TOF-MS is a powerful analytical tool because it can provide the localized information of chemical structures which are irradiated by laser equipped in LDI-TOF-MS [100]. As a model organic contaminant, $\mathrm{B}[\mathrm{a}] \mathrm{P}$, which is one of the common organic contaminants on $\mathrm{Si}$ wafer, was analyzed with LDI-TOF-MS by using ZnO/RGO nanohybrid structures [98]. The roles of $\mathrm{ZnO}$ and $\mathrm{RGO}$ in $\mathrm{ZnO} / \mathrm{RGO}$ nanohybrid structures are to absorb UV light from laser and transfer the energy to analytes [101], and to enrich organic contaminants such as polyaromatic hydrocarbons from $\mathrm{Si}$ wafers through $\pi-\pi$ interaction [102-104]. By optimizing the composition $\mathrm{ZnO} / \mathrm{RGO}$ hybrid structures and their amount used, $\mathrm{B}[\mathrm{a}] \mathrm{P}$ was successfully analyzed with LDI-TOF-MS without interference in low mass region and its LOD was estimated to be $13 \mathrm{pmol}$, which was lower than the concentration of residual organic contaminations generated in the fabrication process of semiconductor devices (Figure $8 \mathrm{~b}, \mathrm{c}$ ). The $\mathrm{ZnO} / \mathrm{RGO}$ nanohybrid structure was also proven to be an effective material for LDI-TOF-MS analysis of other aromatic and aliphatic species on a semiconductor wafer.

a)
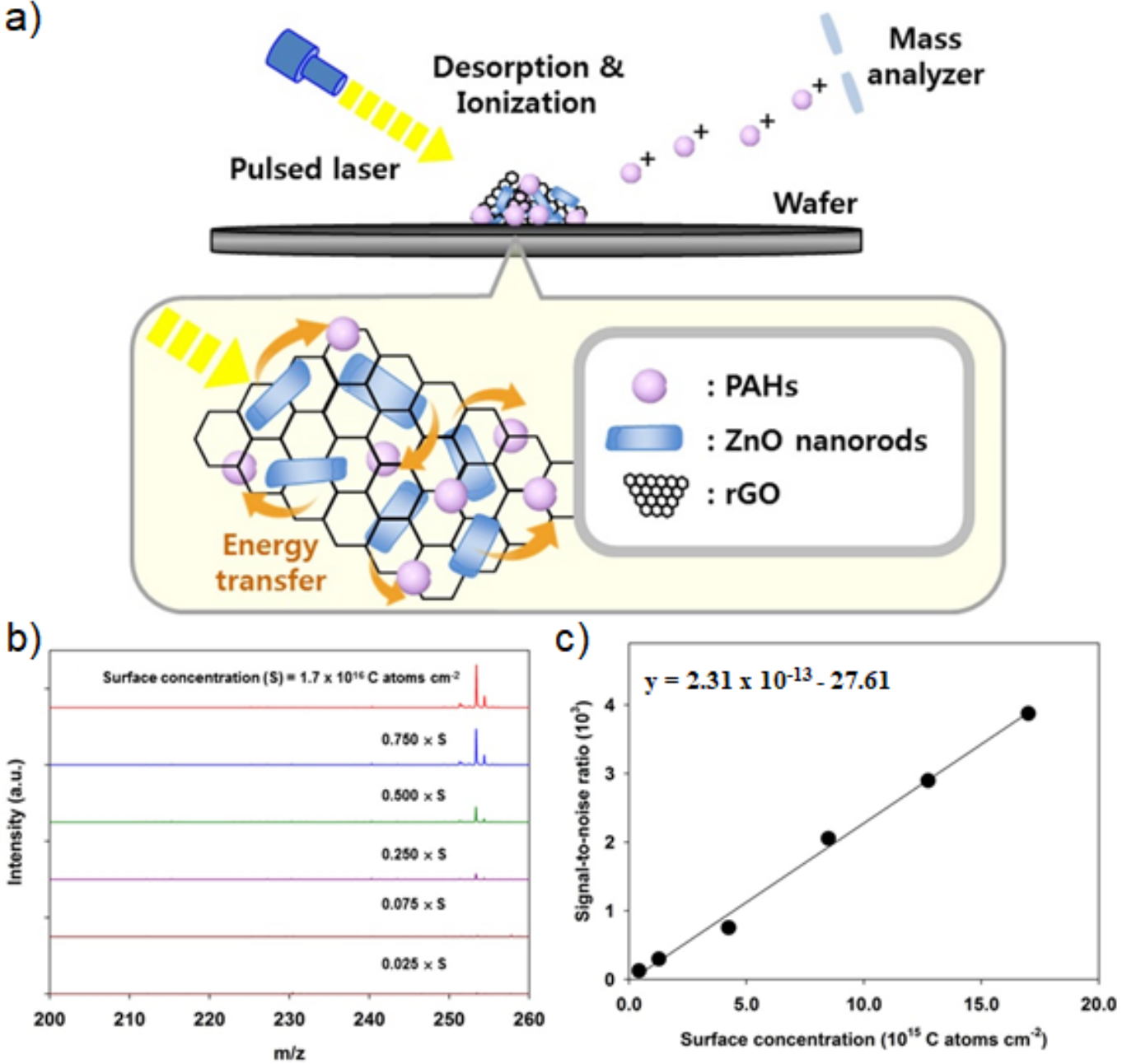

Figure 8. (a) Schematic diagram of the structure and LDI-TOF-MS application of ZnO/RGO nanohybrid structures. (b) LDITOF-MS spectra and (c) standard concentration curve of $\mathrm{B}[\mathrm{a}] \mathrm{P}$ obtained with $\mathrm{ZnO} / \mathrm{RGO}$ nanohybrid structures with different concentration. Adapted with permission from ref. [93]. Copyright (2018) Elsevier. 
As a summary of the important LDI-TOF-MS analytical platforms fabricated by using GO derivatives and their nanohybrid structures, the figure of merit (FOM) of those analytical platforms such as LOD values was described in Table 1 . The summarized results indicated that the hybridization of CNT, metal and metal oxide nanomaterials on the surface of GO derivatives does not always guarantee the improvement of LOD values, but it can still endow their nanohybrid structures with a novel function and thus extend their analytical applicability according to the purposes. The strengths, weaknesses, opportunities and threats (SWOT) analysis was also carried out on the basis of the reviewed literature (Table 2). GO derivatives and their nanohybrid structures have exhibited many advantages including high laser energy absorption capacity, photothermal conversion efficiency, electrical and thermal conductivity, affinity to important biomolecules and environmental pollutants, and amenable surface for functionalization and hybridization with other functional groups and nanomaterials. However, they also possess disadvantages such as laser induced fragmentation, contamination of mass spectrometer, and heterogeneous lateral dimension and chemical structures.

Table 1. A summary of various analytes and their LOD values for different types of $\mathrm{GO}$ derivatives and their nanohybrid structures for LDI-TOF-MS analysis of small molecules.

\begin{tabular}{|c|c|c|c|}
\hline Platform & Analytes & LOD & Ref. \\
\hline RGO films & OCDD & $1 \mathrm{pmol}$ & [61] \\
\hline GO & Flavonoids & $1 \mathrm{pmol}$ & [63] \\
\hline \multirow{3}{*}{ NGO } & BDPD & $50 \mathrm{pmol}$ & \multirow{3}{*}{ [64] } \\
\hline & $\mathrm{B}[\mathrm{a}] \mathrm{P}$ & $600 \mathrm{pmol}$ & \\
\hline & PBA & $70 \mathrm{nmol}$ & \\
\hline bwGO & Amino acids and saccharides & $10 \mathrm{pmol}$ & [67] \\
\hline \multirow{3}{*}{$\begin{array}{l}\text { GO/MWCNT-NH } H_{2} \text { hybrid } \\
\text { films }\end{array}$} & Leu-enkephalin & $1 \mathrm{pmol}$ & \multirow{3}{*}{ [71] } \\
\hline & Saccharides & $10 \mathrm{pmol}$ & \\
\hline & Amino acids & $100 \mathrm{pmol}$ & \\
\hline \multirow{6}{*}{$\begin{array}{l}\text { Multi-layered } \\
\text { GO/MWCNT-NH }{ }_{2} \text { hybrid } \\
\text { films }\end{array}$} & Cellobiose & & \multirow{6}{*}{ [72] } \\
\hline & Leu-enkephalin & 10 pmol & \\
\hline & Phenylalanine & & \\
\hline & Glucose & & \\
\hline & Lysine & $100 \mathrm{pmol}$ & \\
\hline & Leucine & & \\
\hline Au/PAA-GO film & Saccharides and amino acids & $100 \mathrm{pmol}$ & [82] \\
\hline $\begin{array}{c}\text { LBL assembled Au NPs/RGO } \\
\text { hybrid films }\end{array}$ & Amino acids & $150 \mathrm{pmol}$ & [85] \\
\hline $\begin{array}{l}\text { AuNPs/GO porous hybrid } \\
\text { bead }\end{array}$ & N-linked glycopeptide & $2 \mathrm{fmol}$ & [88] \\
\hline $\begin{array}{c}\mathrm{Fe}_{3} \mathrm{O}_{4} @ \text { @graphene oxide } \\
\text { nanocluster }\end{array}$ & Glimepiride & $26 \mathrm{pmol}$ & [97] \\
\hline ZnO-RGO hybrid & $\mathrm{B}[\mathrm{a}] \mathrm{P}$ & $13 \mathrm{pmol}$ & [98] \\
\hline
\end{tabular}


Table 2. A SWOT analysis result of GO derivatives and their nanohybrid structures for LDI-TOF-MS analysis of small molecules.

\begin{tabular}{|c|c|}
\hline Strengths & Weaknesses \\
\hline $\begin{array}{ll}\text { - } & \text { Optical absorption capacity. } \\
\text { - } & \text { Photothermal conversion efficiency } \\
\text { - } & \text { Electrical and thermal conductivity } \\
\text { - } & \text { Tailorable surface for hybridization with } \\
\text { metal, metal oxide, and semiconductor } \\
\text { nanomaterials. } \\
\text { - Affinity to biomolecules and } \\
\text { environmental pollutants }\end{array}$ & $\begin{array}{ll}\text { - } & \text { Fragmentation induced by laser } \\
\text { irradiation } \\
\text { - } & \text { Contamination of mass spectrometer } \\
\text { - } & \text { Heterogeneous lateral dimension and } \\
\text { chemical structures }\end{array}$ \\
\hline Opportunities & Threats \\
\hline $\begin{array}{ll}\text { - } & \text { Applicability to metabolomics } \\
\text { - } & \text { Applicability to environmental } \\
\text { monitoring } & \\
\text { - } & \text { Compatibility with high-throughput } \\
\text { analysis } & \text { Imaging mass spectrometry }\end{array}$ & $\begin{array}{ll}\text { - } & \text { Potential toxicity of graphene derivatives } \\
\text { - } & \text { Dangerous and toxic chemicals used for } \\
\text { synthesis of graphene derivatives } \\
\text { - } \quad \text { Unstandardized synthetic process and } \\
\text { properties of graphene derivatives }\end{array}$ \\
\hline
\end{tabular}

\section{Conclusions}

Over the past decades, GO derivatives have been extensively investigated to develop an efficient and multi-functional LDI-TOF-MS platform based on their high laser energy absorption capacity, photo-thermal conversion efficiency, thermal conductivity, tailorable surfaces, affinity toward aromatic compounds, salt tolerance, reproducibility, and large surface area. In addition, their excellent intrinsic properties can be considerably enhanced by their surface functionalization and subsequent nanohybridization with other functional carbon, metal and metal oxide nanomaterials. Inspired by these interesting characteristics, we have systematically reviewed the synthesis, structure and property relationship, surface functionalization, assembly, and nanohybridization of GO derivatives for their efficient and diverse applications to LDI-TOF-MS analysis of important low molecular-weight compounds. Although there are many kinds of nanomaterials which have been efficiently utilized for LDI-TOF-MS analysis, GO derivatives and their nanohybrid structures can provide distinct advantages and thus they will considerably contribute to various research fields including metabolomics, environmental pollution, imaging mass spectrometry, and drug discovery. However, the potential toxicity, dangerous and toxic synthetic process and unstandardized structures of GO derivatives should be addressed for their wide-spread applications. Taken together, we believe that the GO-based nanohybrid structures can provide distinct advantages from other nanomaterials and thus will be an important, practical and functional tool for LDI-TOF-MS analysis with their steady progress.

Author Contributions: Conceptualization, Y.-K.K. and S.K.; software, Y.-K.K. and S.-W.K.; writingoriginal draft preparation, S.-W.K., S.K. and Y.-K.K.; writing-review and editing, S.-W.K., S.K. and Y.-K.K.; supervision, Y.-K.K.; project administration, Y.-K.K. and S.K., funding acquisition, Y.-K.K. and S.K. All authors have read and agreed to the published version of the manuscript.

Funding: This work was supported by the National Research Foundation of Korea (NRF) grant funded by the Korea government, Ministry of Science and ICT (MSIT) (No. 2020R1F1A1070831).

Acknowledgments: We appreciate Dongguk University for their kind support for this project.

Conflicts of Interest: The authors declare no conflict of interest. 


\section{References}

1. Liu, T.; Belov, M.E.; Jaitly, N.; Qian, W.J.; Smith, R.D. Accurate mass measurements in proteomics. Chem. Rev. 2007, 107, 3621-3653. [CrossRef] [PubMed]

2. Gao, X.; Tan, B.H.; Sugrue, R.J.; Tang, K. MALDI mass spectrometry for nucleic acid analysis. Top. Curr. Chem. 2013, 331, 55-77. [CrossRef] [PubMed]

3. Hyzak, L.; Moos, R.; Von Rath, F.; Wulf, V.; Wirtz, M.; Melchior, D.; Kling, H.W.; Köhler, M.; Gäb, S.; Schmitz, O.J. Quantitative matrix-assisted laser desorption ionization-time-of-flight mass spectrometry analysis of synthetic polymers and peptides. Anal. Chem. 2011, 83, 9467-9471. [CrossRef] [PubMed]

4. Karas, M.; Bahr, U.; Giessmann, U. Matrix-assisted laser desorption ionization mass spectrometry. Mass Spectrom. Rev. 1991, 10, 335-357. [CrossRef]

5. Aebersold, R.; Goodlett, D.R. Mass spectrometry in proteomics. Chem. Rev. 2001, 101, 269-295. [CrossRef]

6. Guo, Z.; Zhang, Q.; Zou, H.; Guo, B.; Ni, J. A method for the analysis of low-mass molecules by MALDI-TOF mass spectrometry. Anal. Chem. 2002, 74, 1637-1641. [CrossRef]

7. Silina, Y.E.; Volmer, D.A. Nanostructured solid substrates for efficient laser desorption/ionization mass spectrometry (LDI-MS) of low molecular weight compounds. Analyst 2013, 138, 7053-7065. [CrossRef]

8. Chiang, C.K.; Chen, W.T.; Chang, H.T. Nanoparticle-based mass spectrometry for the analysis of biomolecules. Chem. Soc. Rev. 2011, 40, 1269-1281. [CrossRef]

9. Kawasaki, H.; Sugitani, T.; Watanabe, T.; Yonezawa, T.; Moriwaki, H.; Arakawa, R. Layer-by-layer self-assembled mutilayer films of gold nanoparticles for surface-assisted laser desorption/ionization mass spectrometry. Anal. Chem. 2008, 80, 7524-7533. [CrossRef]

10. McLean, J.A.; Stumpo, K.A.; Russel, D.H. Size-selected (2-10 nm) gold nanoparticles for matrix assisted laser desorption ionization of peptides. J. Am. Chem. Soc. 2005, 127, 5304-5305. [CrossRef]

11. Brodoceanu, D.; Elnathan, R.; Prieto-Simón, B.; Delalat, B.; Guinan, T.; Kroner, E.; Voelcker, N.H.; Kraus, T. Dense arrays of uniform submicron pores in silicon and their applications. ACS Appl. Mater. Interfaces 2015, 7, 1160-1169. [CrossRef] [PubMed]

12. Zhu, Q.; Wang, Z.; Wang, Y.; Teng, F.; Du, J.; Dou, S.; Lu, N. Investigation of surface morphology on ion desorption in SALDI-MS on tailored silicon nanopillar arrays. J. Phys. Chem. C 2020, 124, 2450-2457. [CrossRef]

13. Zhu, Q.; Teng, F.; Wang, Z.; Wang, Y.; Lu, N. Confining analyte droplets on visible Si pillars for improbing reproducibility and sensitivity of SALDI-TOF MS. Anal. Bioanal. Chem. 2019, 411, 1135-1142. [CrossRef] [PubMed]

14. Wang, X.; Teng, F.; Wang, Y.; Lu, N. Rapid liquid-phase microextraction of analytes from complex samples on superwetting porous silicon for onsite SALDI-MS analysis. Talanta 2019, 198, 63-70. [CrossRef] [PubMed]

15. Rainer, M.; Qureshi, M.N.; Bonn, G.K. Matrix-free and material-enhanced laser desorption/ionization mass spectrometry for the analysis of low molecular weight compounds. Anal. Bioanal. Chem. 2011, 400, 2281-2288. [CrossRef] [PubMed]

16. Chen, S.; Zheng, H.; Wang, J.; Hou, J.; He, Q.; Liu, H.; Xiong, C.; Kong, X.; Nie, Z. Carbon nanodots as a matrix for the analysis of low-molecular-weight molecules in both positive- and negative-ion matrix-assisted laser desorption/ionization time-of-flight mass spectrometry and quantification of glucose and uric acid in real samples. Anal. Chem. 2013, 85, 6646-6652. [CrossRef] [PubMed]

17. Xu, S.; Li, Y.; Zou, H.; Qiu, J.; Guo, Z.; Guo, B. Carbon nanotubes as assisted matrix for laser desorption/ionization time-of-flight mass spectrometry. Anal. Chem. 2003, 75, 6191-6195. [CrossRef]

18. Tang, H.W.; Ng, K.M.; Lu, W.; Che, C.M. Ion desorption efficiency and internal energy transfer in carbon-based surface-assisted laser desorption/ionization mass spectrometry: Desorption mechanism(s) and the design of SALDI substrates. Anal. Chem. 2009, 81, 4720-4729. [CrossRef]

19. Lu, M.; Yang, X.; Yang, Y.; Qin, P.; Wu, X.; Cai, Z. Nanomaterials as assisted matrix of laser desorption/ionization time-of-flight mass spectrometry for the analysis of small molecules. Nanomaterials 2017, 7, 87. [CrossRef]

20. Liu, Q.; Cheng, M.; Jiang, G. Mildly oxidized graphene: Facile synthesis, characterization, and application as a matrix in MALDI mass spectrometry. Chem. Eur. J. 2013, 19, 5561-5565. [CrossRef]

21. Kim, Y.K.; Min, D.H. Mechanistic study of laser desorption/ionization of small molecules on graphene oxide multilayer films. Langmuir 2014, 30, 12675-12683. [CrossRef] [PubMed]

22. Wei, J.; Buriak, J.M.; Siuzdak, G. Desorption-ionization mass spectrometry on porous silicon. Nature 1999, 399, 243-246. [CrossRef] [PubMed]

23. Nakamura, Y.; Soejima, $\mathrm{T}$. $\mathrm{TiO}_{2}$ Nanocoral structures as versatile substrates for surface-assisted laser desorption/ionization mass spectrometry. ChemNanoMat 2019, 5, 447-455. [CrossRef]

24. Lewis, W.G.; Shen, Z.; Finn, M.G.; Siuzdak, G. Desorption/ionization on silicon (DIOS) mass spectrometry: Background and applications. Int. J. Mass Spectrom. 2003, 226, 107-116. [CrossRef]

25. Thomas, J.J.; Shen, Z.; Crowell, J.E.; Finn, M.G.; Siuzdak, G. Desorption/ionization on silicon (DIOS): A diverse mass spectrometry platform for protein characterization. Proc. Natl. Acad. Sci. USA 2001, 98, 4932-4937. [CrossRef] [PubMed]

26. Sweetman, M.J.; Mclnnes, S.J.P.; Vasani, R.B.; Guinan, T.; Blencowe, A.; Voelcker, N.H. Rapid, metal-free hydrosilanisation chemistry for porous silicon surface modification. Chem. Commun. 2015, 51, 10640. [CrossRef] 
27. Luo, G.; Chen, Y.; Siuzdak, G.; Vertes, A. Surface modification and laser pulse length effects on internal energy transfer in DIOS. J. Phys. Chem. B 2005, 109, 24450-24456. [CrossRef]

28. Wang, X.N.; Tang, W.; Gordon, A.; Wang, H.Y.; Xu, L.; Li, P.; Li, B. Porous $\mathrm{TiO}_{2}$ film immobilized with gold nanoparticles for dual-polarity SALDI MS detection and imaging. ACS Appl. Mater. Interfaces 2020, 12, 42567-42575. [CrossRef]

29. Zhu, Q.; Teng, F.; Wang, Z.; Wang, Y.; Lu, N. Superhydrophobic glass substrates coated with fluorosilane-coated silica nanoparticles and silver nanoparticles for surface-assisted laser desorption/ionization mass spectrometry. ACS Appl. Nano Mater. 2019, 2, 3813-3818. [CrossRef]

30. Min, Q.; Zhang, X.; Chen, X.; Li, S.; Zhu, J.J. N-Doped graphene: An alternative carbon-based matrix for highly efficient detection of small molecules by negative ion MALDI-TOF-MS. Anal. Chem. 2014, 86, 9122-9130. [CrossRef]

31. Huang, X.; Liu, Q.; Huang, X.; Nie, Z.; Ruan, T.; Du, Y.; Jiang, G. Fluorographene as a mass spectrometry probe for highthroughput identification and screening of emerging chemical contaminants in complex samples. Anal. Chem. 2017, 89, 1307-1314. [CrossRef] [PubMed]

32. Zhao, H.; Li, Y.; Wang, J.; Cheng, M.; Zhao, Z.; Zhang, H.; Wang, C.; Wang, J.; Qiao, Y.; Wang, J. Dual-Ion-Mode MALDI MS Detection of small molecules with the O-P,N-Doped carbon/graphene matrix. ACS Appl. Mater. Interfaces 2018, 10, 37732-37742. [CrossRef] [PubMed]

33. Wang, D.; Jiamg, X.; Li, J.; He, B.; Liu, Q.; Hu, L.; Jiang, G. 3D printing of graphene-doped target for "matrix-free" laser desorption/ionization mass spectrometry. Chem. Commun. 2018, 54, 2723-2726. [CrossRef] [PubMed]

34. Huang, X.; Liu, Q.; Fu, J.; Nie, Z.; Gao, K.; Jiang, G. Screening of toxic chemicals in a single drop of human whole blood using ordered mesoporous carbon as a mass spectrometry probe. Anal. Chem. 2016, 88, 4107-4113. [CrossRef]

35. Zhou, D.; Guo, S.; Zhang, M.; Liu, Y.; Chen, T.; Li, Z. Mass spectrometry imaging of small molecules in biological tissues using graphene oxide as a matrix. Anal. Chim. Acta 2017, 962, 52-59. [CrossRef]

36. Shi, C.; Deng, C.; Zhang, X.; Yang, P. Synthesis of highly water-dispersible polydopamine-modified multiwalled carbon nanotubes for matrix-assisted laser desorption/ionization mass spectrometry analysis. ACS Appl. Mater. Interfaces 2013, 5, 7770-7776. [CrossRef]

37. Lu, W.; Li, Y.; Li, R.; Shuang, S.; Dong, C.; Cai, Z. Facile synthesis of N-Doped Carbon dots as a new matrix for detection of hydroxy-polycyclic aromatic hydrocarbons by negative-ion matrix-assisted laser desorption/ionization time-of-flight mass spectrometry. ACS Appl. Mater. Interfaces 2016, 8, 12976-12984. [CrossRef]

38. Han, X.; Li, S.; Peng, Z.; Al-Yuobi, A.O.; Bashammakh, A.S.O.; El-Shahawi, M.S.; Leblanc, R.M. Interactions between carbon nanomaterials and biomolecules. J. Oleo Sci. 2016, 65, 1-7. [CrossRef]

39. Perreault, F.; Fonseca De Faria, A.; Elimelech, M. Environmental applications of graphene-based nanomaterials. Chem. Soc. Rev. 2015, 44, 5861-5896. [CrossRef]

40. Yu, S.; Wang, X.; Yao, W.; Wang, J.; Ji, Y.; Ai, Y.; Alsaedi, A.; Hayat, T.; Wang, X. Macroscopic, spectroscopic, and theoretical investigation for the interaction of phenol and naphthol on reduced graphene oxide. Environ. Sci. Technol. 2017, 51, 3278-3286. [CrossRef]

41. Yu, Y.; Murthy, B.N.; Shapter, J.G.; Constantopoulos, K.T.; Voelcker, N.H.; Ellis, A.V. Benzene carboxylic acid derivatized graphene oxide nanosheets on natural zeolites as effective adsorbents for cationic dye removal. J. Hazard. Mater. 2013, 260, 330-338. [CrossRef] [PubMed]

42. Claramunt, S.; Varea, A.; López-Díaz, D.; Velázquez, M.M.; Cornet, A.; Cirera, A. The importance of interbands on the interpretation of the Raman spectrum of graphene oxide. J. Phys. Chem. C 2015, 119, 10123-10129. [CrossRef]

43. Cançado, L.G.; Jorio, A.; Martins Ferreira, E.H.; Stavale, F.; Achete, C.A.; Capaz, R.B.; Moutinho, M.V.O.; Lombardo, A.; Kulmala, T.S.; Ferrari, A.C. Quantifying Defects in Graphene via Raman Spectroscopy at Different Excitation Energies. Nano Lett. 2011, 11, 3190-3196. [CrossRef] [PubMed]

44. Gómez, J.; Villaro, E.; Navas, A.; Recio, I. Testing the influence of the temperature, RH and filler type and content on the universal power law for new reduced graphene oxide TPU composites. Mater. Res. Express 2017, 4, 105020. [CrossRef]

45. Dave, S.H.; Gong, C.; Robertson, A.W.; Warner, J.H.; Grossman, J.C. Chemistry and structure of graphene oxide via direct imaging. ACS Nano 2016, 10, 7515-7522. [CrossRef]

46. Dreyer, D.R.; Park, S.; Bielawski, C.W.; Ruoff, R.S. The chemistry of graphene oxide. Chem. Soc. Rev. 2010, 39, 228-240. [CrossRef]

47. Shojaeenezhad, S.S.; Farbod, M.; Kazeminezhad, I. Effects of initial graphite particle size and shape on oxidation time in graphene oxide prepared by Hummers' method. J. Sci. Adv. Mater. Devices 2017, 2, 470-475. [CrossRef]

48. Mouhat, F.; Coudert, F.; Bocquet, M. Structure and chemistry of graphene oxide in liquid water from first principles. Nat. Commun. 2020, 11, 1566. [CrossRef]

49. Brisebois, P.P.; Siaj, M. Harvesting Graphene Oxide-Years: 1859 to 2019 A Review of its Structure, Synthesis, Properties and Exfoliation. J. Mater. Chem. C 2020, 8, 1517-1547. [CrossRef]

50. Chen, D.; Feng, H.; Li, J. Graphene Oxide: Preparation, functionalization, and electrochemical applications. Chem. Rev. 2012, 112, 6027-6053. [CrossRef]

51. Loh, K.P.; Bao, Q.; Eda, G.; Chhowalla, M. Graphene oxide as a chemically tunable platform for optical applications. Nat. Chem. 2010, 2, 1015-1024. [CrossRef] [PubMed] 
52. Guex, L.G.; Sacchi, B.; Peuvot, K.F.; Andersson, R.L.; Pourrahimi, A.M.; Ström, V.; Farris, S.; Olsson, R.T. Experimental review: Chemical reduction of graphene oxide (GO) to reduced graphene oxide (rGO) by aqueous chemistry. Nanoscale 2017, 9, 9562. [CrossRef] [PubMed]

53. Zhang, J.; Zheng, X.; Ni, Y. Selective enrichment and MALDI-TOF MS analysis of small molecule compounds with vicinal diols by boric acid-functionalized graphene oxide. J. Am. Soc. Mass Spectrom. 2015, 26, 1291-1298. [CrossRef] [PubMed]

54. Jiang, B.; Qu, Y.; Zhang, L.; Liang, Z.; Zhang, Y. 4-Mercaptophenylboronic acid functionalized graphene oxide composites: Preparation, characterization and selective enrichment of glycopeptides. Anal. Chim. Acta 2016, 912, 41-48. [CrossRef] [PubMed]

55. Tang, L.A.L.; Wang, J.; Loh, K.P. Graphene-based SELDI probe with ultrahigh extraction and sensitivity for DNA oligomer. J. Am. Chem. Soc. 2010, 132, 10976-10977. [CrossRef] [PubMed]

56. Li, J.Y.; Long, X.Y.; Sheng, D.; Lian, H.Z. Organic molecule-assisted synthesis of $\mathrm{Fe}_{3} \mathrm{O}_{4}$ /graphene oxide nanocomposites for selective capture of low-abundance peptides and phosphopeptides. Talanta 2020, 208, 120437. [CrossRef] [PubMed]

57. Dong, X.; Cheng, J.; Li, J.; Wang, Y. Graphene as a novel matrix for the analysis of small molecules by MALDI-TOF MS. Anal. Chem. 2010, 82, 6208-6214. [CrossRef]

58. Bøggild, P. The war on fake graphene. Nature 2018, 562, 502-503. [CrossRef]

59. Georgakilas, V.; Perman, J.A.; Tucek, J.; Zboril, R. Broad family of carbon nanoallotropes: Classification, chemistry, and applications of fullerenes, carbon dots, nanotubes, graphene, nanodiamonds, and combined superstructures. Chem. Rev. 2015, 115, 4744-4822. [CrossRef]

60. Chang, H.; Tang, L.; Wang, Y.; Jiang, J.; Li, J. Graphene fluorescence resonance energy transfer aptasensor for the thrombin detection. Anal. Chem. 2010, 82, 2341-2346. [CrossRef]

61. Zhou, X.; Wei, Y.; He, Q.; Boey, F.; Zhang, Q.; Zhang, H. Reduced graphene oxide films used as matrix of MALDI-TOF-MS for detection of octachlorodibenzo-p-dioxin. Chem. Commun. 2010, 46, 6974-6976. [CrossRef]

62. Lu, M.; Lai, Y.; Chen, G.; Cai, Z. Matrix interference-free method for the analysis of small molecules by using negative ion laser desorption/ionization on graphene flakes. Anal. Chem. 2011, 83, 3161-3169. [CrossRef] [PubMed]

63. Liu, C.W.; Chien, M.W.; Su, C.Y.; Chen, H.Y.; Li, L.J.; Lai, C.C. Analysis of flavonoids by graphene-based surface-assisted laser desorption/ionization time-of-flight mass spectrometry. Analyst 2012, 137, 5809-5816. [CrossRef] [PubMed]

64. Kim, Y.K.; Min, D.H. The structural influence of graphene oxide on its fragmentation during laser desorption/ionization mass spectrometry for efficient small-molecule analysis. Chem. Eur. J. 2015, 21, 1-8. [CrossRef] [PubMed]

65. Li, Z.; Zhang, W.; Luo, Y.; Yang, J.; Hou, J.G. How graphene is cut upon oxidation? J. Am. Chem. Soc. 2009, $131,6320-6321$. [CrossRef]

66. Hong, Y.L.; Lee, J.; Ku, B.C.; Kang, K.; Lee, S.; Ryu, S.; Kim, Y.K. The influence of oxidative debris on the fragmentation and laser desorption/ionization process of graphene oxide derivatives. New J. Chem. 2018, 42, 12692-12697. [CrossRef]

67. Hong, Y.L.; Seo, T.H.; Jang, H.J.; Kim, Y.K. The effect of oxidative debris on the laser desorption/ionization efficiency of graphene oxide derivates for mass spectrometric analysis of small molecules and synthetic polymers. Anal. Sci. 2019, 35, 1097-1102 [CrossRef]

68. Rourke, J.P.; Pandey, P.A.; Moore, J.J.; Bates, M.; Kinloch, I.A.; Young, R.J.; Wilson, N.R. The real graphene oxide revealed: Stripping the oxidative debris from the graphene-like sheets. Angew. Chem. 2011, 50, 3173-3177. [CrossRef]

69. Lee, J.; Kim, Y.K.; Min, D.H. Laser desorption/ionization mass spectrometric assay for phospholipase activity based on graphene oxide/carbon nanotube double-layer films. J. Am. Chem. Soc. 2010, 132, 14714-14717. [CrossRef]

70. Kim, Y.K.; Min, D.H. Durable large-area thin films of graphene/carbon nanotube double layers as a transparent electrode. Langmuir 2009, 25, 11302-11306. [CrossRef]

71. Kim, Y.K.; Na, H.K.; Kwack, S.J.; Ryoo, S.R.; Lee, Y.; Hong, S.; Hong, S.; Jeong, Y.; Min, D.H. Synergistic effect of graphene oxide/MWCNT films in laser desorption/ionization mass spectrometry of small molecules and tissue imaging. ACS Nano 2011, 5, 4550-4561. [CrossRef] [PubMed]

72. Kim, Y.K.; Min, D.H. Fabrication of alternating multilayer films of graphene oxide and carbon nanotube and its application in mechanistic study of laser desorption/ionization of small molecules. ACS Appl. Mater. Interfaces 2012, 4, 2088-2095. [CrossRef] [PubMed]

73. Decher, G.; Hong, J.D. Buildup of ultrathin multilayer films by a self-assembly process: 11 . Consecutive adsorption of anionic and cationic bipolar amphiphiles and polyelectrolytes on charged surfaces. Ber. Bunsenges. Phys. Chem. 1991, 95, 1430. [CrossRef]

74. Ariga, K.; Hill, J.P.; Ji, Q. Layer-by-layer assembly as a versatile bottom-up nanofabrication technique for exploratory research and realistic application. Phys. Chem. Chem. Phys. 2007, 9, 2319-2340. [CrossRef] [PubMed]

75. Lee, S.W.; Kim, B.S.; Chen, S.; Yang, S.H.; Hammond, P.T. Layer-by-layer assembly of all carbon nanotube ultrathin films for electrochemical applicaions. J. Am. Chem. Soc. 2009, 131, 671-679. [CrossRef]

76. Wu, H.P.; Yu, C.J.; Lin, C.Y.; Lin, Y.H.; Tseng, W.L. Gold nanoparticles as assisted matrices for the detection of biomolecules in a high-salt solution through laser desorption/ionization mass spectrometry. J. Am. Soc. Mass Spectrom. 2009, $20,875-882$. [CrossRef]

77. Duan, J.; Linman, M.J.; Chen, C.Y.; Cheng, Q.J. CHCA-Modified Au nanoparticles for laser desorption ionization mass spectrometric analysis of peptides. J. Am. Soc. Mass Spectrom. 2009, 20, 1530-1539. [CrossRef] 
78. Chiang, C.K.; Lin, Y.W.; Chen, W.T.; Chang, H.T. Accurate quantitation of glutathione in cell lysates through surface-assisted laser desorption/ionization mass spectrometry using gold nanoparticles. Nanomed. Nanotechnol. Biol. Med. 2010, 6, 530-537. [CrossRef]

79. Chen, W.T.; Chiang, C.K.; Lin, Y.W.; Chang, H.T. Quantification of captopril in urine through surface-assisted laser desorption/ionization mass spctrometry using 4-mercaptobenzoic acid-capped gold nanoparticles as an internal standard. J. Am. Soc. Mass Spectrom. 2010, 21, 864-867. [CrossRef]

80. Huang, Y.F.; Chang, H.T. Analysis of adenosine triphosphate and glutathione through gold nanoparticles assisted laser desorption/ionization mass spectrometry. Anal. Chem. 2007, 79, 4852-4859. [CrossRef]

81. Su, C.L.; Tseng, W.L. Gold nanoparticles as assisted matrix for determining neutral small carbohydrates through laser desorption/ionization time-of-flight mass spectrometry. Anal. Chem. 2007, 79, 1626-1633. [CrossRef] [PubMed]

82. Kim, Y.K.; Min, D.H. Preparation of the hybrid film of poly(allylamine hydrochloride)- functionalized graphene oxide and gold nanoparticle and its application for laser-induced desorption/ionization of small molecules. Langmuir 2012, 28, 4453-4458. [CrossRef] [PubMed]

83. Kim, Y.K.; Na, H.K.; Min, D.H. Influence of surface functionalization on the growth of gold nanostructures on graphene thin films. Langmuir 2010, 26, 13065-13070. [CrossRef] [PubMed]

84. Kim, Y.K.; Na, H.K.; Lee, Y.W.; Jang, H.; Han, S.W.; Min, D.H. The direct growth of gold rods on graphene thin films. Chem. Commun. 2010, 46, 3185-3187. [CrossRef] [PubMed]

85. Kuo, T.R.; Wang, D.Y.; Chiu, Y.C.; Yeh, Y.C.; Chen, W.T.; Chen, C.H.; Chen, C.W.; Chang, H.C.; Hu, C.C.; Chen, C.C. Layer-by-layer thin film of reduced graphene oxide and gold nanoparticles as an effective sample plate in laser-induced desorption/ionization mass spectrometry. Anal. Chim. Acta 2014, 809, 97-103. [CrossRef] [PubMed]

86. Hong, M.; Xu, L.; Wang, F.; Geng, Z.; Li, H.; Wang, H.; Li, C.Z. A direct assay of carboxyl-containing small molecules by SALDI-MS on a AgNP/rGO-based nanoporous hybrid film. Analyst 2016, 141, 2712-2726. [CrossRef] [PubMed]

87. Tiwari, P.M.; Vig, K.; Dennis, V.A.; Singh, S.R. Functionalized gold nanoparticles and their biomedical applications. Nanomaterials 2011, 1, 31-63. [CrossRef]

88. Li, J.; Huan, W.; Xu, K.; Wang, B.; Zhang, J.; Zhu, B.; Wu, M.; Wang, J. Gold nanoparticle-glutathione-functionalized porous graphene oxide-based hydrophilic beads for the selective enrichment of N-linked glycopeptides. Microchim. Acta $2020,187$. [CrossRef]

89. Hanamoto, S.; Nakada, N.; Jürgens, M.D.; Johnson, A.C.; Yamashita, N.; Tanaka, H. The different fate of antibiotics in the Thams River, UK, and the Katsura River, Japan. Environ. Sci. Pollut. Res. 2018, 25, 1903-1913. [CrossRef]

90. Mojica, E.R.; Aga, D.S. Antibiotics pollution in soil and water: Potential ecological and human health issues. Encycl. Environ. Health. 2011, 97-110. [CrossRef]

91. Danner, M.C.; Robertson, A.; Behrends, V.; Reiss, J. Antibiotic pollution in surface fresh waters: Occurrence and effects. Sci. Total Environ. 2019, 664, 793-804. [CrossRef] [PubMed]

92. Tang, H.Z.; Wang, Y.H.; Li, S.; Wu, J.; Li, J.W.; Zhou, H.Y.; Gao, Z.X. Graphene oxide composites for magnetic solid-phase extraction of twelve quinolones in water samples followed by MALDI-TOF MS. Anal. Bioanal. Chem. 2019, 411, 7039-7049. [CrossRef] [PubMed]

93. Rusu, A.; Hancu, G.; Uivarosi, V. Fluoroquinolone pollution of food, water and soil, and bacterial resistance. Environ. Chem. Lett. 2015, 13, 21-36. [CrossRef]

94. Turiel, E.; Bordin, G.; Rodriguez, A.R. Trace enrichment of (fluoro)quinolone antibiotics in surface waters by solid-phase extraction and their determination by liquid chromatography-ultraviolet detection. J. Chromatogr. A 2003, 1008, 145-155. [CrossRef]

95. Parsamehr, P.S.; Zahed, M.; Tofighy, M.A.; Mohammadi, T.; Rezakazemi, M. Preparation of novel cross-linked graphene oxide membrane for desalination applications using (EDC and NHS)-activated graphene oxide and PEI. Desalination 2019, 468, 114079. [CrossRef]

96. Iwaki, Y.; Kawasaki, H.; Arakawa, R. Human Serum Albumin-modified $\mathrm{Fe}_{3} \mathrm{O}_{4}$ magnetic nanoparticles for affinity-SALDI-MS of small-molecule drugs in biological liquids. Anal. Sci. 2012, 28, 893-900. [CrossRef]

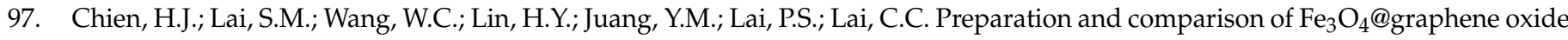
nanoclusters for analysis of glimepiride in urine by surface-assisted laser desorption/ionization time-of-flight mass spectrometry. Anal. Bioanal. Chem. 2020, 412, 4057-4065. [CrossRef]

98. Kim, K.; Um, K.; Yoon, C.; Ryoo, W.S.; Lee, K. Wafer-level detection of organic contamination by ZnO-rGO hybrid-assisted laser desorption/ionization time-of-flight mass spectrometry. Talanta 2018, 182, 273-278. [CrossRef]

99. Tseng, B.H.J.; You, M.D.; Hsin, S.C. Characterization and control of microcontamination for advanced technology nodes and 300-mm wafer processing: Overview and challenges. IEEE Trans. Device Mater. Reliab. 2005, 5, 623-630. [CrossRef]

100. Yan, B.; Kim, S.T.; Kim, C.S.; Saha, K.; Moyano, D.F.; Xing, Y.; Jiang, Y.; Roberts, A.L.; Alfonso, F.S.; Rotello, V.M.; et al. Multiplexed imaging of nanoparticles in tissues using laser desroption/ionization mass spectrometry. J. Am. Chem. Soc. 2013, 135, 12564-12567. [CrossRef]

101. Watanabe, T.; Kawasaki, H.; Yonezawa, T.; Arakawa, R. Surface-assisted laser desorption/ionization mass spectrometry (SALDIMS) of low molecular weight organic compounds and synthetic polymers using zinc oxide (ZnO) nanoparticles. J. Mass Spectrom. 2008, 43, 1063-1071. [CrossRef] [PubMed]

102. Wang, J.; Chen, Z.; Chen, B. Adsorption of polycyclic aromatic hydrocarbons by graphene and graphene oxide nanosheets. Environ. Sci. Technol. 2014, 48, 4817-4825. [CrossRef] [PubMed] 
103. Vállez-Gomis, V.; Grau, J.; Benedé, J.L.; Chisvert, A.; Salvador, A. Reduced graphene oxide-based magnetic composite for trace determination of polycyclic aromatic hydrocarbons in cosmetics by stir bar sorptive dispersive microextraction. J. Chromatogr. A 2020, 1624, 461229. [CrossRef] [PubMed]

104. Zhou, Y.; Apul, O.G.; Karanfil, T. Adsorption of halogenated aliphatic contaminants by graphene nanomaterials. Water Res. 2015, 79, 57-67. [CrossRef] [PubMed] 